\title{
Un viaje al Pacífico Norte: primera empresa institucionalizada novohispana, Cabrillo y Ferrer $(1540-1543)^{1}$
}

\section{A Journey to the North Pacific: First Institutionalized Novohispanian Enterprise, Cabrillo and Ferrer (1540-1543)}

DOI: 10.32870/mycp.v9i25.619

\begin{abstract}
Resumen
A través de este trabajo contribuimos a la ampliación de las fronteras cognitivas, marítimas y territoriales en el ámbito del septentrión novohispano del siglo XVI. Es una más de las aportaciones en una serie que considera los viajes terrestres y los marítimos del norte de la Nueva España. Para lograrlo hacemos uso de la convergencia disciplinaria, metodológicamente utilizamos las herramientas históricas en especial de fuentes primarias, "la Relación”, y las interpretamos desde la perspectiva teórica de la sociología de la ciencia. El resultado del artículo lleva a conocer el desarrollo de una travesía marítima que alcanzó hasta poco más allá del paralelo 40 Norte, así como la toponimia de la Baja y la Alta California y algunas observaciones de la población indígena de la región. Lo relatado en el documento contribuyó a determinar los accidentes geográficos de las costas californianas, con lo cual se expandió la geografía del Pacífico septentrional.

Palabras Clave: Virrey Mendoza, Cabrillo, Ferrer, Pacífico, Baja y Alta California.
\end{abstract}

María Luisa Rodríguez-Sala y Muro²

\begin{abstract}
Through this work, we contribute to enlargement of the cognitive, maritime and territorial borders in the field of the North New Spain of the sixteenth century. It is one of the contributions in a series that considers land and maritime travel from the North of New Spain. To achieve this we make use of the disciplinary convergence, methodologically use historical tools of primary sources, especially in the case "La Relación", and interpret them from the theoretical perspective of the sociology of science. The result of the article leads to know some observations of the indigenous population of the region and the development of a sea-crossing that reached up to little beyond the 40 North parallel, as well as the toponymy of Baja and Alta California. As reported in the document, it helped to determine the landforms of the Californian coasts, which expanded the geography of the North Pacific.
\end{abstract}

Keywords: Viceroy Mendoza, Cabrillo, Ferrer, Pacific, Baja and Alta California.

Artículo recibido el 21 de febrero de 2019 y dictaminado el 07 de mayo de 2019.

1. Este trabajo forma parte de la línea de investigación: "El Perfil de la Ciencia y del Científico en México: Pasado y Presente” y se inscribe en el proyecto de PAPIIT: 301716: Científicos, Técnicos y otros Personajes Forjadores del Desarrollo Social y Cultural de la Nueva España y el México Independiente (Hasta 1870), Sus Roles Sociales y Profesionales.

2. Universidad Nacional Autónoma de México (UNAM), Instituto de Investigaciones Sociales. Circuito Mario de la Cueva s/n, Ciudad de la Investigación en Humanidades, Ciudad Universitaria, C. P. 04510, Coyoacán, CDMX, México. ORCID: http://orcid.org/0000-0002-9302-4866. Correo electrónico: rsala@sociales.unam.mx 


\section{Presentación}

En este trabajo damos a conocer el viaje de Juan Rodríguez Cabrillo al Pacífico septentrional novohispano. Partimos de la consulta de un documento inédito, la "Relación" de ese viaje que es de autoría de un Juan Páez, si bien suponemos se debe a la pluma del piloto Bartolomé Ferrer. Con base en este documento centramos nuestra atención en la descripción de un viaje que estuvo auspiciado institucionalmente por la corona española a través de su virreinato novohispano. A lo largo de la descripción, lo comentamos, en muchos de sus momentos, para compaginarlo con las ubicaciones de los diferentes accidentes geográficos por ellos mencionados. Así es como contemporizamos y actualizamos el desenvolvimiento de la travesía.

La metodología seguida es la que corresponde a la vinculación entre una verdad histórica - el viaje y la figura de Rodríguez Cabrillo-, y una historia de la ciencia, que encierra diferentes verdades históricas. La información la obtuvimos en fuentes primarias hasta ahora poco conocidas. La interpretación está dada desde la mirada de una historia social de la ciencia que da a conocer, por un lado, los aportes que, a diferentes disciplinas, proporcionó el descubrimiento de las costas e islas por las cuales navegaron los expedicionarios y, por otro, a la figura del capitán de la travesía. No dejamos de lado considerar que, a partir de esa mirada social, tanto el capitán Rodríguez Cabrillo, como el piloto Ferrer, fueron unos más de los integrantes del grupo ocupacional de los marinos y expedicionarios. Un conjunto de individuos que unieron a su práctica, el interés por descubrir incógnitas geográficas y que, en el desenvolvimiento de ese objetivo, supieron, tan acertadamente, desempeñar sus roles ocupacionales. Roles que, en su parte más destacada, señalan la necesidad, siempre presente, de someterse a una disciplina jerarquizada en las actividades marítimas, su observancia a raja tabla, permitió llevar a buen término las finalidades a ellos encomendadas por la autoridad suprema, el virrey en turno. Sobre el personaje central, presentamos una breve biografía que parte de los escasos datos que sobre el militar y marino existen y que los analizamos desde la perspectiva de la prosopografía como método de análisis histórico que incluimos en nuestra línea de investigación. Se busca destacar el desarrollo de las acciones y quehaceres de cada sujeto y se vuelve de verdadera utilidad socio-histórica cuando facilita la comparación y contraste entre varios individuos del mismo grupo o de grupos diferentes y pertenecientes a una época o periodo histórico. Emplear este análisis con nuestro personaje central 
señala hacia una continuidad con numerosos personajes de nuestra historia de la ciencia que hemos trabajado a lo largo de nuestra línea de investigación. Considerar así a Rodríguez Cabrillo nos proporciona un elemento más para establecer, en algún momento, esa prosopografía de todas estas figuras.

\section{Desarrollo institucional}

Las dos primeras expediciones que apoyó y organizó la institución que representaba el primer virreinato novohispano a la cabeza del cual estuvo Antonio de Mendoza y Pacheco, y por tanto, con carácter institucionalizado, no fueron exitosas desde la perspectiva económica y material. Se trató de la expedición terrestre a cargo de Francisco Vázquez de Coronado y la marítima encomendada a Hernando de Alarcón y a Melchor Díaz. A pesar de los claros y por ello decepcionantes reportes de los dos recorridos, Mendoza no perdió la esperanza de otros logros más positivos.

Su insistencia obedeció a dos motivaciones: interna y externa. La primera, mantener el desempeño de su rol social y ocupacional como promotor de expediciones con una muy posible oculta inclinación por la aventura, propia de ese Renacimiento que concluía. La externa y abierta y, además propia del momento, por un lado, continuar la búsqueda del estrecho para acortar la travesía marítima este-oeste; por el otro, conquistar y colonizar los territorios septentrionales novohispanos. A consecuencia de las narraciones de Álvar Núñez Cabeza de Vaca, se despertaron las ambiciones de los hombres fuertes del momento: Cortés, Alvarado y Hernando de Soto. Cada uno, por diferentes razones se consideraron con derecho para conquistar y colonizar aquellas tierras que se imaginaba eran muy superiores en extensión y riquezas a la Nueva España. Cada uno logró la autorización de la Corona, la cual veía en estas concesiones la oportunidad de beneficios a un muy bajo costo.

Así, se gestó una nueva empresa en la cual se unieron: la institución virreinal con todos sus rasgos de poder político, económico y social con el dinero, la experiencia y el interés ocupacional de uno de los conquistadores, Pedro de Alvarado. No fue un compromiso sencillo, llevaba mucho fondo que se manifiesta en el amplio texto de la capitulación que celebraron los dos personajes. Ya elhechomismodeque el virreyse trasladara a un apartado poblado michoacano -Tiripitío- para firmar el acuerdo, es revelador de su importancia. Como se desprende del documento, era el Adelantado 
Alvarado quien poseía el derecho inicial a la exploración, de ahíque, al virrey, quien ya habíainiciadolaexpedición, leconviniera sellar el convenio.

La flota que tan bien tenía abastecida y preparada Alvarado consistía de doce embarcaciones, de ellas nueve naves ancladas en el puerto de Santiago de Buena Esperanza. Las otras tres eran una fragata, una galera y una fusta surtas en Acapulco. Todas ellas ya provistas degente depieycaballoydebidamente aprovisionadas con bastimentos. Una vez celebrado el convenio, Alvarado condujo sus navíos al puerto de "Navidad" o de "La Purificación" en Jalisco para desde ese sitio emprender la navegación hacia las costas del septentrión. Fue su última parada antes de acudir al llamado del gobernador Cristóbal de Oñate, acción en la cual, como bien se sabe, perdióla vida el 4 de julio de 1541 ysus consecuencias para los descubrimientos fueron inmediatas, la exploración concertada con el virrey quedó automáticamente truncada. Sin embargo, Mendoza no podía cejar ya en su empeño y, en cierta forma favorecido por la ruptura del convenio, tomó de éste lo que le resultó más conveniente, algunas de las embarcaciones. Seis las destinó al viaje hacia las "Islas de la Especiería" y otras dos ala exploración de las costas septentrionales occidentales de la Nueva España.

\section{Juan Rodríguez Cabrillo toma el relevo de Pedro de Alvarado}

A Rodríguez Cabrillo correspondió el desempeño del rol social de navegante y explorador en unas costas, en gran parte, totalmente incógnitas y con ello, en sus primeras latitudes, la continuidad de la grandiosa empresa geográfica que realizó Ulloa en torno a la península bajacaliforniana. El éxito de Rodríguez Cabrillo no fue menor, ya que geográfica y náuticamente amplió el conocimiento de esa costa californiana al poner por primera ocasión en el mapa mundial, lo que más adelante se denominaría la Alta California. Sobre Rodríguez Cabrillo hemos escrito, hace algunos años un interesante estudio. ${ }^{3}$ Ahora, volvemos a él, pero con nuevos materiales primarios y secundarios, incursionamos en las realizaciones de este infortunado español que, junto con su piloto, dejaron sus vidas en aquellas elevadas latitudes de la América Septentrional Occidental.

3. Véase Rodríguez-Sala, Gómezgil y Cué (1993). 


\section{¿Quién fue Rodríguez Cabrillo?}

Muy pocos son los datos biográficos que sobre este sencillo militar hemos podido recabar, sin embargo, la historiografía ha realizado avances en cuanto a la discusión sobre su origen. Su naturaleza fue tratada por primera ocasión por el cronista español, su contemporáneo, Antonio de Herrera y Tordesillas (Herrera y Tordesillas, 1601-1615) en su clásica obra. Este autor se refiere al navegante como Juan Rodríguez Cabrillo Portugués y ha sido a partir de esta mención que los subsecuentes trabajos lo consideran de origen lusitano. En 1986 el historiador norteamericano Harry Kelsey concluyó que era factible que hubiera nacido en España, escribe: "probablemente en Sevilla; sin embargo, es posible que haya nacido en Cuéllar", no proporciona fecha exacta de nacimiento y tan solo señala que vio la luz primera en una familia humilde, alrededor de 1498 o 1500 (Kelsey, 1998) y que sus padres trabajaban en la casa de un importante comerciante sevillano. Años antes, en 1973, Michael W. Mathes realizó un muy bien documentado trabajo en el cual se ocupa del origen de Rodríguez Cabrillo (Mathes, 1973). La consulta de estos dos estudios no deja duda del origen español de Rodríguez Cabrillo.

No seha podido precisar la fecha en que entró al servicio de la corona española,posiblementelo hayahechopara poder participar en laempresa conquistadora del Nuevo Mundo. Es muy posible que para 1518 Rodríguez Cabrillo se haya trasladado a Cuba en compañía de Pedro de Alvarado. No hay duda de que de la isla antillana pasó a la Nueva España con la gente de Pánfilo de Narváez, enviada por el gobernador de Cuba, Diego Velázquez, en persecución de Cortés. Llevaba ya el cargo de capitán de un reducido grupo de ballesteros, esto es, se adentraba en el rol de miliciano; pisó suelo mexicano el 23 de abril de 1520 cerca de la Villa Rica de la Vera Cruz. Como todos los hombres de Narváez, él también se incorporó a las huestes de Cortés y con el conquistador se trasladó a los alrededores de la gran Tenochtitlán.

Un poco más tarde le encontramos mencionado por Bernal Díaz del Castillo (Díaz del Castillo, 1955) como el capitán que junto con otros tres hombres de mar fueron encargados de elaborar la pez para brear los bergantines que se construyeron para el ataque a la capital azteca.

A propósito, Mathes (1973) escribe que figuró bajo el mando de Juan Rodríguez Villafuerte en la construcción de los trece bergantines que se utilizaron 
en la conquista de la gran Tenochtitlán en agosto de 1521. Le encontramos ya incursionando en tareas y acciones vinculadas a la navegación. Su acción en esta empresa le rindió buenos frutos y en los dos años siguientes acompañó a Francisco de Orozco en la campaña para sojuzgar los pueblos de Oaxaca. De acuerdo con Hernández Sánchez-Barba, Cortés informó que sucedió esto en mayo de 1522(Cortés \& Hernández, 1963). Más adelante estuvo con Alvarado en la pacificación de Tutepec y a partir de ese momento continuó al servicio del gobernador de Guatemala y Honduras. Colaboró con él en diversas campañas por lo que recibió algunas compensaciones como los tributos de Cobán. Mathes amplía esta información y escribe que para el 12 de agosto de 1524 fue recibido por el Cabildo de Santiago de Guatemala como residente en la ciudad y se estableció como colono en Guatemala (García, 1934).

Conocemos que Rodríguez Cabrillo regresó a España en 1524 para contraer matrimonio con doña Beatriz Sánchez de Ortega, hermana de uno de sus compañeros de armas Diego Sánchez de Ortega (Archivo General de Indias [AGI], Justicia, 280). Existen varias noticias sobre los descendientes del matrimonio, que no vienen al caso incluir aquí.

A su regreso a Guatemala en 1529 Rodríguez Cabrillo recibió una encomienda en Cobán en donde explotó las minas cercanas a Uzpantlán y Tequiziztlán con su cuñado. En 1536, cuando residía en Gracia de Dios, Alvarado le concedió las encomiendas de Teota y Cotela (Archivo General de Indias [AGI], Escribania).

Después de este último año la vida de Rodríguez Cabrillo queda vinculada estrechamente con las tareas náuticas en su rol de marino. Su sucesiva contribución al campo exploratorio estuvoligada a sus conocimientos marinos los cuales fueron aprovechados por Cortés y Alvarado. Desde luego que Rodríguez Cabrillo no fue un marino con estudios ni con una larga práctica, se formó sobre la marcha y su participación en la larga y dura travesía a las Californias se debe entender a partir de sus tareas militares, de su estrecha vinculación con el Adelantado Alvarado y con la ambición natural de todo residente y colono de la Nueva España.

Rodríguez Cabrillo asumió su rol social como marino y responsable plenamente hacia 1540, cuando el ya entonces nombrado Adelantado de Guatemala le encomendó la vigilancia de la construcción de la flota que navegaría por el Pacífico. Rodríguez Cabrillo fue uno de los conductores de las naves en su traslado desde el astillero de Acajutla en El Salvador hasta los dos puertos de la Nueva España: Acapulco y Santiago. Es más, 
poco antes de morir, Alvarado lo había nombrado capitán general de la flota y al fallecimiento de éste, el virrey Mendoza respetó la designación, seguramente, conocedor de la valía de Rodríguez Cabrillo como marino, le encomendó la parte de la empresa que debería reconocer las costas occidentales de California y el mando de dos de las naves que había preparado Alvarado y que a su muerte pasaron al virrey Mendoza. Las naves escogidas fueron, como la capitana la "San Salvador" y como segunda o almiranta, la fragata llamada "Victoria". El piloto mayor fue Bartolomé Ferrer o Ferrelo, originario de Levante, uno de los pilotos fue Bartolomé Fernández, en tanto que los maestres fueron Antonio Carrera y S. Remo. La información de estos especialistas encargados de la navegación la encontramos mencionada por el historiador de la época, Antonio de Herrera y Tordesillas (Herrera y Tordesillas, 1601-1615).

Los navíos que se emplearon fueron pequeños y poco aptos para la difícil navegación que enfrentarían, a pesar de lo cual, alcanzaron una latitud extrema para ese tipo de navegación. Sin duda que el éxito deba atribuirse a la experiencia náutica de los responsables de esta exploración Rodríguez Cabrillo y centralmente, los dos pilotos.

\section{El Viaje de Rodríguez Cabrillo y de Ferrer}

Ha sido gracias a la descripción que en su momento se realizó sobre el viaje como ha perdurado hasta nosotros el conocimiento entonces adquirido. Ha sido atribuida por algunos autores a un tal Juan Páez (Archivo General de Indias [AGI], Patronato, 20,N.5,R.13), sin poder precisar quién fue este personaje. Lo más seguro es que haya sido escrita por el piloto mayor, Bartolomé Ferrer, a quien correspondió continuar la travesía a la muerte de Rodríguez Cabrillo. El documento original lleva el título:

Relación hecha por Juan Páez, sobre el descubrimiento que hizo Juan Rodríguez, navegando por la contra-costa del Mar del Sur al Norte. Para su viaje salió del puerto de la Navidad el 27 de junio de 1542.

Contamos con copias del manuscrito en la "Colección Muñoz" y la Relación fue publicada en español en Buckingham Smith, Colección de Varios Documentos para la Historia de la Florida y Tierras Adyacentes, Tomo I (Smith, 1857). El documento original se encuentra en el Archivo General de Indias, puede 
consultarse en línea y así lo hemos realizado, ampliándolo con las anotaciones que al mismo realizó el historiador norteamericano Herbert Eugene Bolton y que se refieren, fundamentalmente, a la identificación de su toponimia con la actualmente conocida. Este autor, a su vez, debe mucha de la información relativa a la ubicación geográfica a su colega Davidson, según testimonia el propio Bolton. El documento que nosotros hemos transcrito y empleado corresponde al inglés Buckingham Smith, en el cual, como dijimos, se publicó la Relación en español. Al parecer la transcripción se debe a Martín Fernández de Navarrete, cuando menos hay una nota por él firmada. Nosotros la hemos cotejado cuando teníamos alguna duda con el original del archivo sevillano; la Relación que incluimos como apéndice de este trabajo.

El original de la Relación es, desde la perspectiva estilística, un documento muy sencillo y escueto, producto de la mano de un individuo con una formación muy simple y que bien puede corresponder a la de un militar sin estudios, producto de la práctica, como sin duda lo fueron Cabrillo y Ferrer. La redacción es repetitiva con un limitado vocabulario que da cuenta concisa de los avances cotidianos en la navegación. Expresa las medidas de su recorrido en leguas y señala con frecuencia, de las coordenadas, tan sólo la latitud que era, desde luego la única dimensión que en esos tiempos se manejaba y en la que considera se localizaban los sitios en donde surgían o a los que llegaban. Con frecuencia da cuenta de la observación o presencia de los naturales, pero los comentarios sobre los indígenas son limitados con escasos aportes antropológicos y/o etnológicos, pero, debe quedar claro, que sí los hay dentro del texto.

La travesía, en su parte inicial, siguió, en términos generales, el derrotero del viaje previo de Francisco de Ulloa hasta, aproximadamente los $30^{\circ}$ latitud norte. El adelanto que podemos otorgar al recorrido de Rodríguez Cabrillo sobre el de Ulloa, consiste en determinar con una mayor exactitud geográfica, la mayor parte de los puntos que tocaron los navegantes anteriores y asignarles denominaciones a aquellos sitios que no precisó Ulloa. Tal fue el caso de la actual y pequeña Isla de San Roque, descubierta antes, pero hasta el viaje de Rodríguez Cabrillo designada con el nombre de Santana, o bien otra, la cercana a la Isla de Cedros a la que llamaron San Esteban y ahora se conoce como Isla de la Natividad en latitud $27^{\circ} 53^{\prime}$.

Durante lo que nosotros consideramos como la primera parte del recorrido de Rodríguez Cabrillo su principal aportación científica radicó 
en esa mejor precisión de los accidentes geográficos que, en una forma u otra, ya eran conocidos. Sin embargo, Rodríguez Cabrillo y su piloto Ferrer aportaron una clara definición y una mejor toponimia, aunadas a breves, pero concisas descripciones de la naturaleza de las costas e islas. No hay nuevas aportaciones etnográficas y antropológicas, ya que durante esta etapa del viaje no tuvieron la oportunidad de contar con la presencia de los habitantes naturales de la zona. Señaladas estas características generales entramos de lleno en la expedición marítima que dio a conocer, a la cartografía mundial, las costas bajacalifornianas y especialmente las de la Alta California, hasta aquel momento totalmente ignoradas y desconocidas, pero en las cuales vivían sus pobladores originarios, indígenas con una incipiente cultura comparada con la del mundo español, pero con un modo de vida y de actuar propios de su naturaleza y entorno geográficos.

La navegación se inició un 27 del mes de junio de 1542 y partieron desde el puerto de Navidad en las actuales costas de la entidad federativa de Jalisco, sitio conocido actualmente como Barra de Navidad un poco al norte del puerto de Manzanillo y en coordenadas $19^{\circ} 12^{\prime} \mathrm{N}$ y $104^{\circ} 40^{\prime}$ O. Desde ese sitio navegaron con rumbo noroeste durante un día y una noche para alcanzar el Cabo Corriente en una distancia de rumbo norte de 40 leguas sobre la costa, aproximadamente 220 kilómetros; llevaron vientos del sureste. Los dos días siguientes continuaron la misma dirección y avanzaron 35 leguas más para llegar el domingo, 2 de julio cuando tuvieron a la vista la California, probablemente se encontraban frente a las costas de Mazatlán, altura en la cual resulta relativamente fácil el cruce hacia la península; lo efectuaron para el lunes siguiente debido a las condiciones climáticas poco favorables y surgieron en la punta de la California. Seguramente se referían a lo que en la actualidad conocemos como Palmillas, sitio aún alejado de la punta geográfica de la península, el Cabo de San Lucas. En ese lugar permanecieron dos días y para el jueves siguiente anclaron precisamente en el puerto de San Lucas en donde tomaron agua y volvieron a partir al anochecer; lo consideraron como puerto limpio y fondable en una tierra pelada y doblada; lo situaron en $23^{\circ}$; sus coordenadas reales son $22^{\circ} 53^{\prime} \mathrm{N}$ y $109^{\circ} 54^{\prime} \mathrm{O}$.

Continuaron el viaje remontando la costa norte desde el Cabo San Lucas en dirección a la hermosa Bahía de la Magdalena, que, por cierto, no se corresponde exactamente a la actual, aunque debió de haber quedado en 
las cercanías. Después de 5 leguas ${ }^{4}$ salieron a la costa el sábado siguiente, 8 del mes, en la punta de la Trinidad. Desde la costa vieron que al interior se apreciaban sierras altas e peladas e dobladas y permanecieron en ese lugar hasta el miércoles siguiente, ya que el tiempo del oeste al noroeste no les era propicio para continuar viaje. La Trinidad, a donde llegaron el miércoles 12 , la ubicaron en $25^{\circ} \mathrm{N}$ y frente a ella escribieron de la existencia de una isla de unas diez leguas de longitud y dos de latitud, la situaron en la banda del sureste y el puerto lo consideraron limpio y fondable, pero sin agua ni leña. Más adelante mencionan el Puerto de San Pedro en $25.5^{\circ}$ y en esa altura navegaron por la costa que hace una gran ensenada, el cabo de la cual está en 26 grados y citan un sitio más, la Bahía de San Martín antes del puerto de la Magdalena a 40 leguas de la bahía antes dicha y en donde estuvieron el miércoles 19 de julio. Por las descripciones, sin duda estaban en las inmediaciones de la actual Bahía de Magdalena, si bien, las coordenadas no se corresponden, las actuales son $24^{\circ} 35^{\prime} \mathrm{N}$ y $112^{\circ} 00^{\prime} \mathrm{O}$.

Un día después, el jueves partieron de ese puerto y continuaron su navegación a lo largo de la costa con vientos muy ruines y a las 6 leguas encontraron un surgidero detrás de una punta a la que llamaron Punta de Santa Catalina. Continuaron en la misma forma su recorrido con rumbo norte y para el martes 25 del mismo mes, descubrieron una bahía grande en los 27 grados y medio en una distancia de 23 leguas de la Bahía de Magdalena; en esa altitud encontraron el puerto que bautizaron como Puerto de Santiago muy cerca del cual toparon con unos bajos muy peligrosos y de peña a los que llamaron Habreojo, precisamente por el requerimiento de "abrir los ojos" para no encallar. Pueden muy bien corresponder a la actual Punta de Abreojos que se localiza en latitud de $26^{\circ} 42^{\prime} \mathrm{N}$ y $113^{\circ} 25^{\prime} \mathrm{O}$ y marca la entrada a la Laguna de San Ignacio, la gran reserva de la biósfera que es visitada por las ballenas grises para la procreación de la especie.

La navegación de Rodríguez Cabrillo continuó a lo largo de la costa hasta el grado 28 de acuerdo a sus medidas y ahí surgieron al abrigo de una punta en donde volvieron a ver arboledas, las que no habían tenido a la vista desde la Punta de California. El terreno era de sierras altas y fragosas y denominaron al lugar Santa Ana en donde vieron una isleta en distancia de una legua de la tierra.

4. Es muy posible que haya un error en el manuscrito, puesto que esta distancia de 5 leguas es muy escasa para haber alcanzado los 25 grados. 
Para el jueves 27 continuaron navegando desde ese punto para volver a anclar en un puerto que llamaron Puerto Fondo debido al mucho fondo que junto a la costa tenía y que correspondía a cerca de 30 brazas y era limpio. Al día siguiente, viernes, partieron de él, pero tuvieron que regresar en tres ocasiones debido a que el mal tiempo no les permitió avanzar y permanecieron en el puerto hasta el lunes siguiente, el 31 de julio, día de San Ignacio.

El primer día del mes de agosto dejaron ese lugar y navegaron cosa de 10 leguas para volver a echar anclas en un nuevo puerto al que denominaron San Pedro Vincula a la vista de la gran Isla de Cedros, la que ubicaron en 28 grados y medio largos, la tierra la encontraron alta, fragosa e pelada y anotaron en esa altura que desde California no habían tenido a la vista ningún Indio. Muy cerca de esa isla, a 4 leguas y más cercana a la tierra localizaron, otra isla, la llamaron San Esteban y puede muy bien corresponder a la actual Isla de la Natividad cuya ubicación coincide con la que marcaron los navegantes. De ella escriben que hace una ensenada grande que no parece tierra y que tenía una buena canal con mucha yerba sobre el agua que se creía en el fondo y está pegado abajo. Consideraron que tendría unas tres leguas de redondez o de boj y un buen puerto y ahí permanecieron hasta el sábado 5 de agosto.

Sin embargo, poco más al sur y unos días antes ya habían tocado tierra en lo que ahora forma parte del territorio, más allá del paralelo 28, límite geográfico entre las dos entidades peninsulares mexicanas, la Baja California Sur y la Baja California. El primer sitio descubierto por Rodríguez Cabrillo en la segunda fue un buen puerto al que llamaron de Santa Clara y que se corresponde con la actual Punta María, aproximadamente 17 leguas al noreste de su punto de partida en el extremo norte de la Isla de Cedros. Fue en este lugar en donde avistaron a unos pocos indígenas, quienes huyeron ante la presencia de los extraños. Navegaron varios días con vientos escasos a lo largo de una costa limpia y fondable con tierra pelada y no fragosa, con llanuras y valles.

Como era de esperarse pasaron a anclar frente a la Isla de Cedros en donde permanecieron hasta el jueves 10 del mes y tomaron agua y leña, pero tampoco encontraron naturales, aunque hallaron rastros de ellos. Según sus mediciones, Cedros estaba en $19^{\circ}$ y su punta de sotavento quedaba en la banda del sur en donde se localizaban buenos puertos con agua y leña, pero de tierra pelada. Calcularon que su longitud en la banda sur sería de 
12 leguas; su superficie real es de 347 kilómetros cuadrados y su puerto se distingue en la actualidad por ser el de salida para el comercio exterior de la gran producción de sal de las cercanas salinas de Guerrero Negro.

Para el día 13 estaban ya en lo que llamaron Punta de Malabrigo en una ensenada, según ellos, en altura de los 30 grados y medio y se corresponde, muy probablemente, con la actual Punta Canoas en latitud de $29^{\circ} 25^{\prime} \mathrm{N}$. Poco después hacia el miércoles 16 de agosto una vez recorridas cerca de 10 leguas en seis días llegaron a una pequeña isla a la que llamaron de San Bernardo y la midieron en $30^{\circ} \mathrm{N}$; fue descrita como de buen parecer ya que presentó una costa limpia con buen puerto de reparo y tierra adentro vieron valles con algunos árboles, pero también tierra pelada. A pesar de parecer buen sitio no vieron Indios. Se corresponde con la actual de San Jerónimo, localizada en latitud de $29^{\circ} 48^{\prime} \mathrm{N}$ a la entrada de la Bahía Rosario. Poco más adelante de la isla en donde permanecieron algunos días, encontraron un nuevo accidente geográfico la Punta del Engaño, actual Punta Baja, que marca el final de la bahía.

Al domingo siguiente, día 20 de agosto, salieron de la isla de San Bernardo para llegar a la Punta del Engaño a 7 leguas de distancia y en $31^{\circ}$ $\mathrm{N}$ con una dirección de noroeste al sureste con relación a la isla. Podría tratarse de la punta de costa en altura del actual poblado de El Rosario, más o menos cercano a la costa en altura de $29^{\circ} 50^{\prime} \mathrm{N}$. Toda la semana siguiente continuaron la costa y a unas 10 leguas de la última punta descubrieron un buen puerto en el cual surgieron para tomar agua y leña con algo de monte y según ellos en $31.5^{\circ} \mathrm{N}$.

\section{La Primera Toma de Posesión de la California}

Dos días más tarde, el martes 22 de agosto, se produjo un acontecimiento de primera importancia en la navegación y memorable en la historia del Pacífico Norte. El capitán Rodríguez Cabrillo bajó a tierra para tomar posesión de ella en nombre del rey y del virrey y al puerto que escogieron le puso, como era de esperarse, el nombre de Puerto de la Posesión con una laguna en donde pescaban unos naturales, quienes en cuanto vieron a los españoles, salieron huyendo. Tomaron a uno de ellos y le dieron algunos rescates y lo dejaron ir. Este puerto ha sido identificado por los historiadores como el poblado de San Quintín, ya en Baja California Norte, en latitud 30² $24^{\prime} \mathrm{N}$. 
Precisamente en estas costas, también se produjo el primer encuentro de relativa importancia con los habitantes de la zona. Los españoles habían permanecido en el puerto para realizar algunas reparaciones a las velas y tomar agua, siempre muy cercanos a la costa. El jueves, guiados por el humo de las hogueras se dirigieron en el batel a ese sitio y encontraron al primer grupo de unos 30 indígenas pescadores. Algunos de ellos, en forma muy tranquila, les acompañaron inclusive a bordo de las embarcaciones. A la vista de los españoles les informaron, por señas, que habían visto a otros hombres como ellos que tenían barbas y traían perros y ballestas $y$ espadas que estaban a 5 jornadas tierra adentro. Muy probablemente se referían a noticias que pudieron haber recibido de los miembros de alguno de los grupos que dos años antes habían reconocido el otro extremo de la Península, el de Hernando de Alarcón o el de Melchor Díaz. Los indígenas fueron descritos como gente crecida y dispuesta, tenían el cuerpo untado con un betún blanco por los muslos, cuerpo y brazos, sus pinturas los hacían ver como si llevaran calzas y jubones acuchillados, portaban armas parecidas a las de los mexicanos e iban ataviados con pieles de venados preparadas en la misma forma en que los indígenas de la Nueva España arreglaban sus cotaras o calzado. Llevaban armas parecidas a las de los mexicanos con sus pedernales en las flechas. El Capitán les entregó una carta para que la llevaran a los españoles que decían que había tierra adentro.

Del Puerto de la Posesión salieron el domingo 27 de agosto y a partir de ahí la expedición fondeo aún en varios puntos más hasta dejar costas actualmente mexicanas a la altura de las Islas Coronado frente a las playas de la ciudad de Tijuana. Destacamos aquí cuáles fueron los lugares bajacalifornianos de la Península, descubiertos por Rodríguez Cabrillo: La actual Isla de San Martín, denominada por los navegantes como de San Agustín a la cual llegaron el 27 de agosto y de la cual escribieron que tendría dos leguas de redondez. Continuaron barloventeando hasta el día 30 y regresaron a la isla en donde hallaron rastro de gente, restos de animales y de árboles muy gruesos que había arrojado el mar, según ellos, se trataba de cipreses y cedros. Para principios de septiembre, el domingo 3, se alejaron de la Isla de San Agustín y navegaron en derrota de norte a sur hasta el jueves 7 cuando fondearon en una ensenada en donde terminaba la costa de norte a sur y se volvía al noroeste. Ahí encontraron un valle muy grande, tierra llana y sierras altas con tierra buena, con costa bravas. Para el viernes 8 del mes pasaron por un buen cabo al que llamaron Cabo de San Martín, 
seguramente frente al actual cañón de Santo Tomás, al que describieron como un sitio en donde hacen remate unas sierras altas que vienen detrás $y$ comienzan otras sierras pequeñas, mencionaron la presencia de un valle grande y otros pequeños con buena tierra y con un puerto limpio y fondable al que llamaron de San Martín. Mencionaron que ahí vuelve la costa al noroeste. En ese sitio cuando tomaban agua llegaron 40 indios con sus armas y flechas, desnudos y llevaban maguey asado y pescado para comer, la consideraron gente crecida. En este punto tomaron una nueva posesión de la tierra y permanecieron ahí hasta el lunes siguiente, 12 del mes, cuando continuaron navegando varias leguas para salir a fondear en una banda que denominaron Cabo de Cruz en $33^{\circ} \mathrm{N}$, sin agua ni leña y tampoco vieron Indios. Ya fuera de ese cabo continuaron por la costa del noroeste y sureste y vieron unos Indios en unas canoas muy pequeñas; la tierra es muy alta y pelada e seca y desde California hasta este sitio la consideraron tierra de arenales a la mar y desde aquí empieza la tierra en otra arte, que es tierra de bermejales y de mejor parecer. ${ }^{5}$

Algunos días después, el domingo 17 de septiembre, navegaron a lo largo de la extensa Punta Banda a la que llamaron Cabo de la Cruz y que marca la entrada a la actual bahía y puerto de Ensenada en la entidad mexicana de Baja California. Sobre ella hay una interesante descripción que corresponde a la naturaleza de las tierras que la circundan y que hacen fondo al buen puerto que bautizaron como San Mateo y del cual tomaron posesión, en algún día entre el domingo 17 y el viernes 22 del mes de septiembre de 1542. Dice al texto:

En este puerto tomaron agua en una laguna de agua llovediza y hay arboledas como de ceibas, excepto que es madera recia, hallaron maderas gruesas e grandes que traía la mar...es buena tierra al parecer, hay grandes sabanas e la yerba como la de España, ${ }^{6}$ y es tierra alta y doblada; vieron unas manadas de animales como ganados que andaban de ciento en ciento y más que parecían a obejas del Perú y la lana luenga, tienen cuernos pequeños de un xeme en largo y tan gordos como el dedo pulgar y la cola ancha y redonda y de largo de un palmo. (AGI, Patronato, 20,N.5,R.13, fol. 10).

5. Bermejales, un bermejal es una extensión grande de terreno de ese color, o sea, rojo.

6. La coincidencia es real, ya que toda esa región de la península de la Baja California y alrededores es considerada con clima tipo mediterráneo, de donde se cultiven con éxito la vid y los olivares y otros productos propios de ese clima. 
Dejaron el puerto de San Mateo hacia finales del mismo mes y en su travesía hacia el norte navegaron a lo largo de la costa durante, aproximadamente, 26 leguas. ${ }^{7}$ Durante el trayecto vieron hermosos valles arbolados en tierra llana y doblada, así como tierras altas en el interior. Con frecuencia llegaron hasta ellos huellas de ser zona habitada debido a las continuas humaredas, sin embargo, nunca encontraron a sus habitantes. En este recorrido pasaron por tres islas despobladas, la una de ellas mayor que las otras y cercanas a tierra firme. Les dieron el nombre de Islas Desiertas y corresponden a las Islas Coronado ubicadas en latitud de $32^{\circ} 25^{\prime} \mathrm{N}$, precisamente frente a la actualmente populosa ciudad fronteriza, Tijuana.

\section{Segunda parte de la travesía de Rodríguez Cabrillo}

Desde nuestra apreciación el viaje de Rodríguez Cabrillo se distingue por una clara segunda parte, la que se corresponde con los descubrimientos geográficos a lo largo de los litorales de la Alta California. No solamente se trata de una frontera geográfica, también como vimos de carácter natural ya que la tierra y el clima cambian drásticamente. Una vez que cruzaron frente a lo que para ellos eran las Islas Desiertas, las actuales Islas Coronado, estaban dejando las tierras ahora mexicanas e internándose en el estado norteamericano de California.

La presencia de la empresa de Rodríguez Cabrillo al destacar por su insistente interés en dar nombre a lo que descubrían, representa, en la actualidad, una marca de origen y el establecimiento de una identidad hispana en lo que ahora es un país anglo, la cual, hasta la fecha se ha mantenido, vía la toponimia española, sin mencionar las crecientes oleadas de migración latinoamericana, especialmente mexicana que se asienta en esa región y que refuerza su origen, lo quieran o no, hispano.

Para el jueves, 28 de septiembre el primero de los lugares descubiertos en la Alta California fue el favorable puerto actual de San Diego al que se dio el nombre de San $\mathrm{Miguel}^{8}$ debido a haber surgido en él a días de que se celebra la fiesta del arcángel San Miguel. Aquí los navegantes nuevamente

7. Aproximadamente 145 kilómetros (1 legua marina equivale a 5.55 kilómetros).

8. La bahía de San Diego y el área que la rodea recibieron su nombre de otro gran navegante, Sebastián Vizcaíno, quien cartografió gran parte de la Alta California para uno de los viajes auspiciados por España y el virreinato de la Nueva España en el año de 1602. Los navegantes acamparon cerca de una aldea indígena que se llamó Nipaguay y tuvieron una misa en honor a San Diego de Alcalá. 
volvieron a tener noticia de la presencia de otros españoles armados en el interior de la región. El bello y magnífico puerto lo localizaron en los 34 grados con un tercio, en realidad sus coordenadas correctas son: $32^{\circ} 42^{\prime} \mathrm{N}$ y $117^{\circ} 09^{\prime} \mathrm{O}$. Después de haber echado anclas frente a él, bajaron a tierra en donde vieron gente, de la cual solo unos cuantos hombres los esperaron, los otros huyeron, pero al anochecer los naturales los flecharon y lograron herir a tres españoles. Estos indios fueron descritos como gente bien dispuesta y crecida, cubiertos con pieles de animales. Durante su estancia en el puerto de San Miguel los navegantes sufrieron un fuerte temporal que los obligó a permanecer hasta el martes 3 del mes de octubre.

Como correspondía a su navegación, Rodríguez Cabrillo continuó su derrota por unas 18 leguas (100 kilómetros) a lo largo de la costa por donde veían muchos valles, llanuras y humaredas y dentro de la tierra muchas sierras. El sábado 7 amanecieron en unas islas cercanas a la tierra a las cuales dieron los nombres de San Salvador y La Victoria. Probablemente sean algunas de las islas en la zona actual de Mission Bay. Aquí, los navegantes pasaron en el batel a tierra y encontraron un buen número de naturales, muchachos y mujeres y algunos de los hombres echaron su canoa y pasaron a la nave española en donde recibieron rescates que les agradaron, se holgaron con ellos.

El domingo 8 del mismo mes, bajaron a tierra en una bahía que llamaron Bahía de los Fumos, pudiera ser a la altura de la actual costa de La Joya, debido a los muchos humos que vieron y en donde los naturales les informaron de nuevo de la presencia de otros españoles; situaron la bahía en los 35 grados y en ella encontraron un buen puerto. Poco más adelante, casi en la misma altura, sólo un tercio de grado más al norte, se encontraron con un bien poblado asentamiento humano cuyos habitantes se desplazaban en canoas para realizar sus pescas; lo bautizaron como Pueblo de las Canoas, cuyo nombre original era el de Xucu y en él Rodríguez Cabrillo decidió enviar dos hombres con cartas en búsqueda de los muchos españoles que los naturales les informaron no se encontraban demasiado alejados.

Sus siguientes encuentros con los naturales fueron bastante cercanos, ya que a lo largo de la costa se desplazaban en sus numerosas canoas; los poblados estaban todos cercanos y los naturales les proporcionaron los 
nombres de cada uno de ellos, mismos que insertaron en su Relación. ${ }^{9}$ Los españoles los consideraron como muy buena tierra, muy buenas llanuras e muchas arboledas e sabanas. Los habitantes andaban vestidos con pellejos de animales y afirmaban que dentro de la tierra había grandes cosechas de maíz y contaban con muchas vacas.

El domingo 15 de octubre pasaron frente a una isla grande de unas 15 leguas de largo, distante de la costa 6 leguas y, aproximadamente 18 del Pueblo de las Canoas. De esta isla, a la que denominaron San Lucas asentaron los indígenas que estaba muy poblada con los siguientes pueblos: Niquipos, Maxul, Xugua, Nitel, Macamo, Nimitapal. Es muy probable que estuvieran frente a la conocida Isla Catalina, de la cual escribieron que estaba a 6 leguas de la tierra y a unas 18 del pueblo antes mencionado. Los siguientes días, lunes y martes, navegaron siempre acompañados de muchas canoas de indígenas a quienes obsequiaron con diferentes cosillas y ellos les proporcionaron sardina fresca $y$ muy buena. Estos naturales iban vestidos de pellejos de animales y llevaban el pelo largo y entremetidos cordeles adornados de pedernales, huesos y madera. El miércoles 18 de noviembre fondearon en un cabo en forma de galera y le nombraron así Cabo Galera ya en 36 grados largos; cerca del mismo descubrieron dos islas, una grande de 8 leguas y la otra de 4, con un buen puerto. Las nombraron Islas de San Lucas y muy posiblemente se correspondan con las actuales de Anacapa, Santa Cruz, Santa Rosa y San Miguel de las numerosas del archipiélago del "Canal" o del "Norte", mejor conocido como de Santa Bárbara. Están situadas, más o menos, frente a las costas de los condados de Ventura, Oxnard y de Santa Bárbara en alrededor de los 33 a los $34^{\circ}$ N. En esta zona estuvieron varios días debido al mal tiempo y observaron que entre los pobladores se daban situaciones de enfrentamientos.

Partieron de las islas para el miércoles 25 de octubre y durante varios días anduvieron navegando aún en dirección noroeste y en uno de ellos tomaron nuevamente posesión del lugar. Continuaron su viaje por unas 10 leguas desde el Cabo de Galeras hasta los 36 grados y medio acorde a sus mediciones. No fondearon en ningún sitio debido a lo brava de la costa, pero notaron que desde los 34 grados hacia el norte, el tiempo era muy similar al de España con mucho frío a las mañanas y a las tardes, y con los temporales, grandes cerrazones y los aires

9. Los nombres de esos poblados locales fueron: Xuco, Bis, Soposo, Alloc, Xabasgua, Xocotoc, Potoltec, Nacbuc, Quelqueme, Mixingua, Misesopano, Elquis, Coloc, Mugu, Xagua, Anacbuc, Partocac, Susuquey, Quanmu, Gua, Asimu, Aguir, Casalic, Tuсuтu е Inсрири. 
pesados. Debieron haber navegado por las costas entre los actuales puertos de Los Ángeles y San Francisco, con costas efectivamente poco accesibles.

Para el primer día de noviembre, el de Todos Santos, se refugiaron en un puerto al que dieron ese nombre y desde ahí se dirigieron al Puerto de las Sardinas que ya habían reconocido para tomar agua y leña. Los siguientes días anduvieron por sitios ya conocidos y lograron navegar hasta lo que ellos situaron en 38 grados y denominaron como Cabo de San Martín. Para el sábado 11 de noviembre perdieron de vista la otra nave y el lunes siguiente reiniciaron la travesía para buscar la embarcación compañera, corrieron al Norte e al Nornoroeste con viento Oeste y Oes Noroeste y se dirigieron a reconocer una tierra muy alta cubierta de árboles y las montañas con nieve y anotaron haber llegado a los $40^{\circ}$. Pero, desde luego, aún no estaban cercanos a esa altitud, sino aún mucho más al sur, probablemente a la altura de Monterey, hacia los $36^{\circ} 36^{\prime} \mathrm{N}$.

Para el jueves 16 mencionan en su documento haber amanecido sobre una ensenada muy grande toda llena de pinos y en los 39 grados, la nombraron Bahía de Pinos y por la situación bien pudieron estar en la actual región de Monterey, en la cual al norte de esa península existe un sitio que conserva aún el nombre de Point Pinos y parecería concordar con el sitio descrito por Rodríguez Cabrillo y compañeros. Los siguientes días navegaron por la zona y se percataron de la existencia de elevadas montañas nevadas por lo cual dieron nombre a ese sitio como Sierras Nevadas y al cabo que salía, desde luego, Cabo de Nieve al que ubicaron en $38^{\circ}$ y dos tercios, posición de dos grados superior a la de la península de Monterey, error totalmente justificable para la época, ya que según especialistas modernos han considerado que el error de altitud variaba entre uno y medio y dos grados.

Consideramos que es esta posición geográfica una de las más septentrionales alcanzadas, si bien pudieron haber seguido casi en forma errabunda hasta el Cabo Mendocino. Escribieron que recorrieron toda la costa desde la Bahía de Pinos hasta las Islas de San Lucas buscando un abrigo, pero no lo encontraron. Fue así como se refugiaron en una de las muchas islas de ese conjunto, a la que habían dado el nombre de Posesión ${ }^{10}$ y en ella, a 3 días del mes de enero de 1543 falleció de esta presente vida Juan Rodríguez Cabrillo, Capitán de los dichos navios. El motivo de su muerte fue el haber sufrido una

10. No hay que confundir esta isla con la primera que llamaron Isla de la Posesión y que fue en donde la empresa de Cabrillo tomó la primera posesión de la tierra, aun mucho más al sur, en la actual península de Baja California. 
caída durante el viaje de ida, a consecuencia de la cual se quebró un brazo a la altura del hombro, herida que se le infectó durante los días siguientes y vino a repercutir en su fallecimiento.

El mando de la empresa pasó a las manos del piloto mayor Bartolomé Ferrer o Ferrelo, originario de Levante en España. El Capitán les encargó mucho al tiempo de su muerte que no dejasen de descubrir cuanto posible fuese por toda aquella costa. La isla fue designada en honor del capitán con su nombre, mismo que no se conserva en la actualidad, pero en cambio sí una larga carretera de California se llama "Cabrillo Highway".

Durante varios de los siguientes días navegaron por esas islas con tiempo muy poco favorable que les obligó a buscar refugio en una u otra isla y así recorrieron varias de ellas. Inclusive regresaron al Puerto de las Sardinas en donde tomaron leña y padecieron fuerte frío, observaron que los naturales se alimentaban solamente de bellotas. Más adelante, sobre el 18 de febrero, llegaron a la Isla de San Salvador que bien puede corresponder a la actual Año Nuevo Island en $\left(37^{\circ} 33^{\prime} \mathrm{N}\right)$ y desde ella vieron seis islas grandes y pequeñas.

Para el 22 de febrero retornaron en la búsqueda del Cabo de Pinos y aun 20 leguas más allá por costas muy bravas y con mal tiempo; no vieron rastros de indios; para el miércoles 28 de ese mes, o sea a finales del mismo, anotaron la altitud de 43 grados, desde luego, exagerada. Pero es muy posible que en viajes un tanto errabundos hayan recorrido, como señalaron, unas 100 leguas marinas, en cuyo caso bien pudieron llegar hasta una altura parecida a la del Cabo Mendocino. ${ }^{11}$ Durante esta parte de la travesía el mal tiempo y la furia del mar hizo peligrar seriamente a las naves, a tal grado que los tripulantes se encomendaron a Nuestra Señora de Guadalupe y ofrecieron varias mandas y después de padecer muchos contratiempos, finalmente, el sábado al medio día, ya en el mes de marzo, abonanzó la mar y percibieron cierta calma. Para el día 5 del mes retornaron a la Isla de Juan Rodríguez con mucho frío y no se atrevieron a tomar el puerto pues el mar estaba sumamente agitado en tal forma que buscaron refugio en la Isla de San Salvador. Esa noche perdieron de vista al navío acompañante y pensaron que el mar se lo había tragado, ya que al amanecer tampoco lo descubrieron; consideraron que habían alcanzado los 44 grados. Esta fue la altura registrada más septentrional y desde ese momento

11. Hay que señalar claramente que en el documento original no se menciona para nada ese sitio, no hay constancia de su designación con ese nombre, que, desde luego, corresponde a reconocimiento del virrey Mendoza. 
la travesía se manifestó en viaje de retorno, así se comprende por los sitios que se mencionan en el documento, ya todos previamente recorridos. Llegaron al Pueblo de las Canoas sin encontrar a la nave Victoria; para el domingo 14 de marzo escriben que allegaron al Puerto de San Miguel sin encontrar a la compañía ni noticias de ella. Permanecieron seis días a la espera; tomaron a dos muchachos en calidad de lenguas para llevarlos a la Nueva España y dejaron varias noticias por si llegaba la nave perdida.

Las siguientes paradas son muy rápidas en recorrido, mencionan la Bahía de San Mateo y luego ya el Puerto de la Posesión, a donde llegaron el 21 del mes y, localizado, como ya se vio, en plena península de la Baja California. La siguiente parada que se consigna es la de la Isla de Cedros a la cual arribaron a la media noche del viernes 23 de marzo. Permanecieron en ella y el lunes siguiente, con gran alegría vieron aparecer a la nave compañía, la cual se había extraviado a la altura de la Isla de Juan Rodríguez en donde estuvo a punto de perderse en unos bajos muy traicioneros. Nuevamente, en ese sitio, los tripulantes se encomendaron a la virgen y prometieron ir desnudos a su santuario. El final de la travesía se consigna rápidamente al escribir en la Relación que:

Lunes a dos días del mes de abril partieron de la Isla de Cedros la vuelta de la Nueva España, porque no tenían bastimentos para tornar acometer a descubrir la costa. Llegaron en el Puerto de Navidad, sábado a 14 días del dicho mes de abril.

Vino por Capitán de los navios Bartolomé Ferrel, Piloto mayor de los dichos navios, en falta de Juan Rodríguez Cabrillo, que murió en la Isla de la Posesión. Venían hombres en los dichos navíos. (AGI, Patronato, 20,N.5,R.13, fol. 15).

Con estos párrafos nos enteramos de que los hombres que participaron en esa empresa, regresaron salvos en los dos navíos: San Salvador y Victoria.

Al viaje que inició como capitán Rodríguez Cabrillo y terminó Ferrer le correspondió el conocimiento y descripción de las costas de las dos Californias, la Baja que comprende la península y la Alta que se corresponde al actual estado de California de los Estados Unidos de América. Desde luego que gran parte de la península había sido ya recorrida por Francisco de Ulloa, pero correspondió al viaje que comentamos, los puntos comprendidos entre los paralelos 30 norte y, según los navegantes, el 43 norte. Sin embargo, como sabemos el cálculo de la latitud no era exacto.

Según el escrito original el último lugar consignado con nombre es el Cabo de Pinos que parece corresponder, como ya dijimos, al extremo noroeste de la península de Monterey en la actual California norteameri- 
cana, en donde se registra un parque que lleva el nombre de Point Pinos. Ese sitio se corresponde con una altitud de casi 37 grados. Sin embargo, el documento narrativo señala algunas travesías laterales al noroeste que abarcaron alrededor de 100 leguas marinas. Escribieron que el domingo 18 de febrero cuando se encontraban en los alrededores de la Isla de San Salvador y al cabo que anduvieron obra de cien leguas hallaron los tiempos más recios y mucha mar. Esta isla podría ser, como ya escribimos atrás, la actualmente llamada Año Nuevo Island en ( $37^{\circ} 33^{\prime} \mathrm{N}$ ) en cuyo caso desde ahí esas 100 leguas llevarían, aproximadamente el viaje de Rodríguez Cabrillo y su sucesor, Ferrer, a alcanzar la altura del Cabo Mendocino, (40 $26^{\circ}$ y $124^{\circ}$ $24^{\prime}$ ), actualmente en el Condado de Humboldt, (Lost Coast), ya que esas 100 leguas marinas se corresponden aproximadamente con 500 kilómetros que sería la distancia alrededor que hay entre esa isla, San Salvador y el Cabo Mendocino. Si bien el autor de la Relación no menciona para nada este último nombre, sí sabemos que ese es el punto más occidental de la costa californiana y que los navegantes anotaron que...e vieron una punta que hacía como remate de tierra que volvía la costa Nornoroeste, lo cual se da en los alrededores de ese cabo.

\section{Epílogo}

La expedición de Rodríguez Cabrillo y la de Ferrer fue la primera que conoció los litorales mexicanos del norte de la península bajacaliforniana y los de la Alta California, ahora territorio norteamericano. Sus aportaciones a la expansión del conocimiento y de las fronteras fueron de especial relevancia, ya que contribuyeron a demostrar la viabilidad náutica en latitudes septentrionales nunca antes alcanzadas en el Mar del Sur. Simultáneamente expandieron las fronteras de las costas septentrionales, tomaron posesión de las tierras e islas descubiertas, anotaron cada uno de los accidentes geográficos y describieron la naturaleza y a los habitantes de las regiones. Es de gran interés constatar que las dos naves en su recorrido pasaron por las numerosas islas que bordean las costas bajacalifornianas y muy especialmente las californianas. La descripción de los recorridos por las numerosas islas del Canal de Santa Bárbara y de otro conjunto más al norte, frente a Monterey, es altamente significativa, ya que dan una clara impresión de esos entornos insulares. Los avatares climáticos que tuvieron que enfrentar en esas alturas y más al norte duran- 
te los meses invernales de enero, febrero y marzo, describen claramente cómo se vieron expuestos al frío, la nieve y las tormentas que los vientos de esas latitudes provocaban. La pérdida o separación de las dos naves, la capitana San Salvador y la segunda, Victoria, describe la angustia y el temor que padecieron sus tripulantes. En igual forma nos enteramos del peligro al que se sintieron enfrentados durante una de las tormentas, a tal grado que se consideraron estar a punto del naufragio y por ello su natural y usual encomienda marina a las fuerzas superiores, en el caso y curiosamente a Nuestra Señora de Guadalupe. ¿Se referían ya a la mexicana virgen recién aparecida al culto en la capital novohispana, en 1531, o bien a la española venerada en el Monasterio de Guadalupe en Extremadura? No es fácil establecer la devoción de referencia; sin embargo, con base en un reciente trabajo de investigación, sabemos que la primera invocación específica a la virgen mexicana procede precisamente de la relación de otro viaje marítimo, el capitaneado por Alonso de Arellano, el cual en su regreso de las Filipinas en el patache "San Lucas" en agosto del año de 1565 a la altura de la California la fuerza del mar los dejó a punto de zozobrar y pidieron a la virgen su socorro y le ofrecieron llevar a cuestas parte de la embarcación a su casa de Guadalupe, en México. Por lo tanto, es muy probable que los marinos de Rodríguez Cabrillo y los de Ferrer hayan implorado a la virgen guadalupana de Extremadura, ya que sufrieron la tormenta 20 años antes y, posiblemente el culto mariano mexicano aún no estaba extendido.

Sin duda una más de las importantes y significativas aportaciones de este fue su casi inmediata repercusión en la cartografía de la época. Según expone Miguel León-Portilla existen claros indicios de que pronto llegaron a España noticias de ese recorrido y que, si bien actualmente no contamos con ningún mapa del mismo, debió haberse enviado alguno a Sevilla, a la Casa de Contratación. La prueba es, escribe León-Portilla (1989), que el historiador Francisco López de Gómara haya dedicado unas cuantas líneas de su Historia de las Indias tan contemporánea como impresa en 1552, a lo que descubrieron la gente del virrey Mendoza. Ese historiador menciona que alcanzaron los $45^{\circ}$ y muchos piensan que por allí se junta la tierra con la China. Además, en su mapa del Nuevo Mundo se delinea la península de la Baja California, mencionando tan solo el lugar de c.b. Vallenas y extendiendo hacia el norte la costa hasta una distancia exagerada con fuerte inclinación hacia el Oeste. De la difusión de la empresa de Rodríguez Cabrillo-Ferrer también quedó temprana impronta en 
el mapa incluido en la obra Delle Navigatione et Viaggi de Ramusio (Ramusio, 1563, p. 38), en la cual se aprecia ya bastante nítidamente el perfil de la Alta California. Existen otros mapas del siglo XVI que nos señalan esos litorales californianos.

Sin embargo, a nivel mundial no fue tanta la difusión dada a esta travesía en su momento ni más tarde, ello motivó que poco tiempo después, a 36 años de distancia, otros navegantes europeos consideraran como uno de sus triunfos náuticos, el recorrido del pirata Francis Drake por esas mismas costas.

Las aportaciones fundamentales del viaje de Rodríguez Cabrillo-Ferrer fueron:

a) El haber ampliado la delimitación geográfica de los litorales occidentales del septentrión hasta una importante latitud norte que sería conocida como la Alta California.

b) La anotación detallada del recorrido, de los accidentes geográficos y del clima contribuyó significativamente a establecer las posibilidades de futuros reconocimientos de la costa septentrional.

c) Se precisó la inexistencia, hasta esa latitud, del estrecho y con ello se intentó despejar parte de la geografía mítica imperante.

d) Las descripciones de la naturaleza y de los escasos habitantes contribuyeron, sin duda alguna, a una mejor idea de las posibilidades para la futura colonización de esos territorios cercanos a las costas reconocidas.

e) De acuerdo con León-Portilla (1989), a pesar de los avances en el conocimiento geográfico que se lograron con ésta y con las anteriores expediciones náuticas como la de Ulloa, aún permanecían grandes dudas acerca de la ubicación de los nuevos territorios septentrionales. Fundamentalmente estaban referidas a la cercanía con las tierras de China y Japón, a la existencia del estrecho entre los dos mares y a la amplitud del nuevo continente en su parte septentrional. Persistía aún una geografía mítica en la que se mantenía la fantasía sobre ciudades e islas de fábula que sólo se empezaría a desvanecer a través de los conocimientos de las expediciones marítimas y terrestres de los siguientes siglos.

f) En el aspecto político el viaje daría lugar, años más adelante, a la preocupación creciente de la corona española por mantener su presencia en las Californias ante la cada vez mayor amenaza de los navegantes ingleses y franceses. 
Serán los aspectos científicos, políticos y comerciales los que mantendrán abierto el camino para la continuidad de las exploraciones por el septentrión novohispano. Corresponderá al siguiente virrey, don Luis de Velasco, inaugurar una nueva etapa, la comercial, con dos vertientes, la del camino a la tierra de las especias y su protección y la empresa de la explotación perlífera en las costas californianas. Pero a ello dedicaremos una posterior etapa de esta investigación en el estudio de la aportación relacionada con nuestro septentrión mexicano.

\section{Referencias}

Archivo General de Indias (AGI). ES.41091.AGI/24.9//JUSTICIA,280, Beatriz Sánchez de Ortega, vecina de la ciudad de Santiago, en la provincia de Guatemala, contra Francisco de la Cueva, teniente de Gobernador de aquella provincia, por haberle quitado los indios del pueblo de Jumaytepeque que tenía en encomienda.

Archivo General de Indias (AGI). ES. 41091.AGI/20//ESCRIBANIA, Juan Rodríguez Cabrillo, vecino de Santiago de Guatemala, contra el fiscal, sobre el derecho a las encomiendas de Coban y Acatenango.

Archivo General de Indias (AgI).ES.41091.AgI/29.3.9.1// PATRONATO,20,N.5,R.13, Relación hecha por Juan Páez, sobre el descubrimiento que hizo Juan Rodríguez, navegando por la contra-costa del Mar del Sur al Norte. Para su viaje salió del puerto de la Navidad el 27 de junio de 1542.

Cortés, H., \& Hernández, S. B. M. (1963). Cartas y Documentos [de] Hernán Cortes. México: Porrúa.

Díaz del Castillo, B. (1955). Historia Verdadera de la Conquista de la Nueva España. México: Fernández Editores.

García, G. J. (1934). Libro viejo de la fundación de Guatemala y papeles relativos a D. Pedro de Alvarado. Guatemala: Bibliotheca Goathemala.

Herrera y Tordesillas, A. (1601-1615). Historia general de los hechos de los castellanos en las islas i tierra firme del mar oceano / escrita por Antonio de Herrera; En quatro decadas desde el año de 1492 hasta el de 531. España: Fondo Antiguo de la Universidad Complutense.

Kelsey, H. (1998). Juan Rodríguez Cabrillo. Estados Unidos de Norteamérica: Huntington Library Press.

León P. M. (1989). Cartografía y Crónicas de la Antigua California. México: Universidad Nacional Autónoma de México, Fundación de Investigaciones Sociales. 
Mathes, M. W. (1973). The Discoverer of Alta California: João Rodrigues Cabrilho or Juan Rodríguez Cabrillo? The Journal of San Diego History, 19(3), 1-8. Ramusio, G. B. (1563). Delle Navigationi et Viaggi (Vol. I, 3 Edición). Venetia, Italia: Nella Stamperia de Giunti.

Rodríguez-Sala, M. L., Gómezgil R.S, I. \& Cué, M.E. (1993). Navegantes, Exploradores y Misioneros en el Septentrión Novohispano en el siglo XVI. México, D.F: Consejo Nacional para la Cultura y las Artes a través del Programa Cultural de las Fronteras e Instituto de Investigaciones Sociales, UNAM. Smith, B. (1857). Colección de Varios Documentos para la Historia de la Florida y Tierras Adyacentes (Tomo I). London: Trübner.

\section{APÉNDICE A}

Relación hecha por Juan Páez, sobre el descubrimiento que hizo Juan Rodríguez, navegando por la contra-costa del Mar del Sur al Norte. Para su viaje salió del puerto de la Navidad el 27 de junio de 1542. ${ }^{12}$

Juan Páez Relación del descubrimiento que hizo

Juan Rodríguez navegando por

la contra costa del Mar del Norte,

llevó dos navíos. ${ }^{13}$

\section{2 de J. Páez Navegación del Mar del Sur al Norte para el año de 1543}

12. El original se encuentra en: AGI, Patronato, 20,N.5,R.13.

13. Transcripción con ortografía modernizada, se conserva el estilo y la puntuación. Los nombres de los lugares se anotan con mayúsculas o destacados.

Procede directamente de la obra: Smith, B. (1857) Colección de Varios Documentos para la Historia de la Florida y Tierras Adyacentes (Tomo I). London: Trübner, en la cual se publicó la relación en español. Al parecer la transcripción se debe a Martín Fernández de Navarrete, cuando menos hay una nota por él firmada.

El original se encuentra en el Archivo General de Indias, PATRONATO,20,N.5,R.13, versión que cotejamos para entregar esta transcripción. Existen dos ejemplares de la relación en el Archivo del Museo Naval de Madrid: Relación de la navegación que hizo Juan Rodríguez desde el Puerto de Navidad para descubrir la costa de la Nueva España en 1542, Depósito hidrográfico, AMN 0147, Ms. 0198/2 y Relación o diario de la navegación que hizo Juan Rodríguez con dos navios al descubrimiento del paso del Mar del Sur al Norte, desde 27 de junio de 1542, que salió del Puerto de Navidad, hasta 14 de abril del siguiente año, que se restituyó a él, habiendo llegado hasta la altura de cuarenta y cuatro grados, con la descripción de la costa, puertos, ensenadas e islas que reconoció y sus distancias, en la extensión de toda aquella costa, Colecciones, AMN 0020,Ms.9928/001. 
Partió Juan Rodríguez del puerto de Navidad para descubrir la costa de la Nueva España a 27 días de junio de 1542

Tardó desde el puerto de Navidad hasta Cabo de Corriente un día e una noche con cuarenta leguas de vientos sueste.

Desde el miércoles hasta el jueves siguiente anduvieron su derrota a luengo de la costa, 35 leguas.

Domingo, a dos días de julio tuvieron vista de la California, tardaron en atravesar por temor de los tiempos que no fueron muy favorables, casi 4 días surgieron el lunes siguiente, a 3 del dho. en la punta de la California e ahí estuvieron dos días, y de ahí fueron al puerto de San Lucas el jueves siguiente e tomaron agua, no vieron estos días indio ninguno. Dicen que está este puerto en 23 grados y es desde la punta al puerto limpio e fondable y es tierra pelada y doblada. ${ }^{14}$

Partieron del puerto de San Lucas el jueves a la noche y el sábado siguiente, al ocho de dicho mes surgieron en la punta de la Trinidad que está en 25 grados, habrá de San Lucas, 5 leguas, es costa limpia y sin requesta ninguna, dentro de la tierra parecen sierras altas e peladas e dobladas, estuvieron surtos aquí por ser los tiempos contrarios de Oeste Nordoeste hasta el miércoles siguiente.

Miércoles, a 12 días del dicho mes partieron de ahí, en el puerto de la Trinidad hace puerto una isla que está ahí y es buen puerto abrigable para los vientos oes noroeste, el puerto de la isla es en la cabeza de la isla de la banda del Sueste y es puerto limpio y fondable, no tiene agua ni leña, tendrá la isla diez leguas de longitud $y$ de latitud 2 leguas, surgieron esa noche.

Partieron el jueves siguiente y pasaron por el puerto de San Pedro que está en 25 grados $y^{1 / 2}$, en este puerto no hay agua ni leña, su travesía es Sueste, tiene buen reparo para Poniente, fueron navegando por la costa que hace una gran ensenada, el cabo de la cual está en 26 grados, es tierra baja e médanos de tierra, costa blanca e limpia: fueron navegando a luego de ella con vientos bonancibles hasta los 27 grados y miércoles a 19 del dicho fueron en tierra a un puerto que hallaron e salidos en tierra hallaron un camino seguido de indios, e fueron por él un tiro de arcabuz donde hallaron una fuente de agua, es tierra llana dentro y pelada y muy seca, pusieron nombre del puerto de la Madalena, habrá 40 leguas de la Bahía de San Martín hasta este puerto.

El jueves siguiente a 20 de dicho partieron de este puerto y fueron navegando a luengo de la costa con vientos ruines y obra de seis leguas de alli hallaron un

14. Cabo San Lucas se encuentra en coordenadas $22^{\circ} 53^{\prime}$ y $109^{\circ} 54^{\prime}$, como puede observarse muy cercana a la señalada en el derrotero. 
surgidero detrás de una punta, que llaman Punta de Santa Catalina, y así anduvieron navegado a luego de la costa. Y el martes siguiente a 25 de dicho mes de julio descubrieron una bahía grande en 27 grados y medio, caminaron muy poco estos días por los ruines tiempos, surgieron en este puerto y pusieron nombre el Puerto de Santiago, habrá del Puerto de la Madalena 23 leguas, están de la Punta de Santiago en cinco leguas unos bajos muy peligrosos, y de peña, y no parecen sino cuando revienta la mar en ellos, están una legua de tierra, y en 27 grados y medio largos, llámanse Habre ojo. Fueron caminando por la misma derrota a luengo de la costa hasta los 28 grados, y allí surgieron al abrigo de una punta. Aquí hay arboledas lo que no vieron desde la Punta de la California, habrá de esta punta al Puerto de Santiago a la punta del Noroeste 23 leguas: son sierras altas y fragosas con algún arboledo, pusimos nombre Santa Ana, tiene una Isleta, habrá una legua de tierra.

Jueves a 27 del dicho partieron del dicho Puerto de Santa Ana e fueron a surgir obra de seis leguas de alli en un puerto que pusieron nombre Puerto Fondo por el mucho fondo que tenía, que junto a tierra había treinta brazas, es limpio, e partieron el otro día siguiente del dicho puerto, e tornaron a arribar tres veces al dicho puerto con tiempos contrarios y estuvieron en el dicho puerto hasta el lunes siguiente.

Lunes 31 del dicho mes partieron del dicho Puerto Fondo e surgieron obra de 8 leguas de allí aquella noche, e otro partieron a su navegación.

Martes, $1^{\circ}$ día de agosto partieron de allí, e anduvieran obra de diez leguas donde surgieron en un puerto que pusieron San Pedro Vincula, está este puerto a vista de la Islas de Zedros, está este puerto en 28 grados y medio largos, es tierra alta y fragosa e pelada, desde California acá no hemos visto Indio ninguno.

Miércoles a 2 del dicho mes partieron desde Puerto y les dio viento contrario y anduvieron volteando, fueron a surgir a una Isla que está de la parte del Sueste de Isla de Zedros cuatro leguas de ella, y está esta dicha isla que llamaron San Esteban con la remate de la punta de la tierra firme Leste Oeste, costa de Noroeste Sueste, está una legua de la tierra firme; de esta punta la tierra firme vuelve la costa hacia Les Nordeste, que hace una ensenada grande que no parece tierra; entre la Isla y la tierra firme, hace buena canal, y han de pasar allegados a la Isla porque hay una restringa de debajo que sale de la punta hasta un cuarto de legua; hay mucha yerba sobre agua que se cría en el fondo, y está pegado abajo; córrese esta Isla con San Pedro Vincula Noroueste Sueste, tendrá esta Isla tres leguas de redondez; estuvimos en esta Isla con viento contrario hasta el sábado siguiente a cinco del dicho mes de agosto; tiene buen puerto de la banda del Sueste, hay mucha pesquería de anzuelo y muchos pájaros. 
Partieron de la Isla de Sant Esteban, sábado 5 de agosto, e fueron a surgir a la Isla de Zedros, donde estuvieron hasta jueves a 10 de dicho mes tomando aguada y leña, no hallaron Indios, aunque hallaron rastro de ellos; está esta Isla en 29 grados la punta de Sotavento de la banda del Sur, y tiene de esta banda del Sur buenos puertos e agua e leña y es de esta parte pelada, no tiene sino unas maticas pequeñas, es Isla grande e alta e pelada, e córrese casi Leste Oeste, y tendrá de longitud de esta banda del Sur, doce leguas. Partieron de la Isla de Zedros, jueves a 10 días de dicho mes de agosto para seguir su viaje; y fueron la vuelta de la tierra firme navegando al Norte, anduvieron este día obra de diez leguas, y el viernes siguiente fueron a surgir a un puerto que llamaron Puerto de Santa Clara, es buen puerto, fueron en tierra y hallaron 4 Indios, los cuales se huyeron, está este puerto en 30 grados escasos, córrese con Isla de Zedros Nordeste Sudeste y córrese esta costa desde el puerto hacia la ensenada Nornoroeste Susureste; es costa limpia y fondable, es tierra pelada e no es fragosa, tiene llanuras y valles, estuvieron en este puerto hasta el domingo a 13 del dicho mes por los ruines vientos.

Domingo, a 13 días del dicho mes partieron de este puerto y fueron navegando a luego de la costa con vientos escasos surgiendo cada noche, y el martes siguiente surgieron en una punta que hace una ensenada que está en (P. 175) 30 grados y medio, tiene muy poco reparo, llamáronle Punta del Malabrigo,

El miércoles siguiente fueron navegando luego de la costa y dióles mucho viento Noroeste que era su contrario y estuvieron al reparo a la noche sin ganar par adelante nada, y el jueves siguiente con aguaceros y contrastes e calmas que no tomaron tierra, y esta noche siguiente tuvieron mucho viento de Oes Noroeste y estuvieron al reparo, y el viernes siguiente anduvieron con vientos, bonanzas y se hallaron a barlovento de la punta de Mal abrigo seis leguas, e así anduvieron hasta el sábado siguiente, a 19 de dicho mes que surgieron en un Isla pequeña, que está a media legua de tierra firme; estará diez leguas de la Punta de Mal abrigo; está en 30 grados y medio, tiene buen surgidero y buen reparo, llamáronle San Bernardo, tendrá una legua de Norte Sur. Córrese la costa de la tierra firme Nornoroeste Susueste y es costa limpia, la tierra adentro es de muy buen parecer, y llama y hay valles buenos e alguna arboleda, y lo otro es pelado; no hallaron estos días Indios.

Domingo 20 del dicho mes de agosto partieron de la Isla de San Bernardo y allegaron a la Punta del Engaño, que estará siete leguas de esta Isla, la cual punta está en 31 grados, córrese la costa de la Punta hacia la Isla Noroeste Susueste; en la Punta del Engaño la tierra no es alta y parece en si buen tierra y llana; las sierras son peladas, no vimos señal de Indios, e así fueron navegando hasta el lunes siguiente siguiendo la costa al Norte e al Nordeste, e obra de diez leguas de la Punta 
del Engaño descubrieron un buen puerto, en el cual surgieron, y tomaron agua e leña, está en 31 grados y medio, es puerto para poder hacer cualquier adobio a los navios poniéndolos a monte.

El martes siguiente el capitán Juan Rodríguez Cabrillo fue en tierra y tomó posesión en ella en nombre de su Magd. y del Il.mo. Señor D. Antonio de Mendoza y le puso nombre el Puerto de Posesión; hallo una laguna que tiene tres......grandes $y$ hallaron algunos Indios pescadores, que luego huyeron; tomaron uno de ellos el cual dándole ciertos rescates le soltaron e se fue; la tierra adentro es tierra alta $y$ doblada e tiene buenos valles e parece ser buena tierra, aunque es pelada; estuvieron en esta tierra hasta el domingo 27 del dicho mes, adobando las velas y haciendo aguada, y el jueves vieron ciertos humos y fueron allá con el batel e hallaron obra de 30 Indios pescadores, lo cuales estuvieron quedos y trujeron al navio un muchacho $y$ dos Indias a los cuales dieron de vestir e rescates y los dejaron ir; de los cuales no pudieron entender nada por señas. ( $p .176$ )

Viernes siguiente yendo a tomar agua hallaron en la aguada ciertos Indios que estuvieron quedos, e les amostraron un xaguey de agua e una salina de sal que había mucha y dijeron por señas que no hacían su habitación allí, sino dentro en la tierra e que había mucha gente. Este dicho día en la tarde vinieron cinco Indios a la playa a los cuales trujeron a los navios y parecieron Indios de razón y entrando en el navio señalaron y contaron los españoles que estaban ahí y señalaron que habian visto a otros hombres como a ellos que tenían barbas y que traían perros $y$ ballestas y espadas; venían los Indios untados con un betún blanco por los muslos y cuerpos y brazos, y traían a manera de cuchilladas puesto el betún, que parecían hombre en calzas e jubones acuchillados, y señalaron que cinco jornadas de allí estaban los españoles; señalaron que había muchos Indios e tenían mucho maíz e papagayos, venían cubiertos con cueros de venados y algunos traían los cueros de venados adobados a manera de como adoban los mexicanos los cueros que traen en la cotaras; es gente crecida y dispuesta; traen sus arcos y flechas como los de la Nueva España, con sus pedernales las flechas; dióles el Capitán una carta para que llevasen a los españoles que decían que había dentro de la tierra.

Partieron de este Puerto de la Posesión domingo a 27 del dicho mes de agosto y navegando su derrota hallaron una Isla dos leguas de tierra firme, es despoblado, hace buen puerto en ella, pusiéronle nombre de San Agustín, tendrá dos leguas de redondez, $y$ anduvieron así luego de la costa con tiempos escasos barloventeando hasta el miércoles siguiente a 30 del dicho mes, que les dio mucho viento de Noroeste, que le hizo arribar a la Isla de San Agustín, en esta Isla hallaron rastro de gente, e dos cuernos de vaca e árboles muy grandes que había echado allí la mar, 
que tenían de longor más de 60 pies y de gordor que no podrán abarcar dos hombre a cada uno, parecen a cipreses e había cedros, era mucha la cantidad de esta madera, no tiene otra cosa, si buen Puerto no está Isla, estuvieron en esta Isla hasta el domingo siguiente.

Domingo a tres días del mes se septiembre partieron de dicha Isla de San Agustín e fueron navegando su derrota, y el lunes siguiente surgieron en la tierra obra de siete leguas a barlovento en costa de Norte Sur, e luego fueron su derrota e fueron navegando con tiempos bonancibles y escasos en costa de Norte Sur hasta el jueves a siete días del dicho mes de septiembre que fueron a surgir en una ensenada que hace la tierra e aqui se acaba la costa de Norte Sur e vuelve al Noroeste, en esta ensenada hace un valle grande y es tierra llana a la costa e dentro hay sierras altas e tierra doblada al parecer buena; toda la costa es brava e aplaselada que media legua de tierra estaban en diez brazas surtos; hay por aquí muchas yerbas que están sobre el agua.

El viernes siguiente a ocho del dicho mes anduvieron con bien, barloventeando $y$ hallaron aquí corrientes contrarias; fueron a surgir a la punta que hace el cabo e hace buen abrigo del Oes Noroeste, pusiéronle el nombre de Cabo de San Martín, hace remate de tierra de una parte e de otra; aquí hacen remate unas sierra altas que vienen detrás y comienzan otras sierras pequeñas; hace un valle grande y otros muchos, al parecer es buena tierra, está en 32 grados y medio y es puerto limpio e fondable, córrese con la Isla de San Agustín Norte Sur.

Estando en este cabo de San Martín fueron en tierra por agua e hallaron una laguna pequeña de agua dulce, donde tomaron agua y en esta aguada vinieron cuarenta Indios con sus arcos e flechas, no se pudieron entender con ellos, venían desnudos, traían maguey asado para comer e pescado, es gente crecida, aquí tomaron posesión, estuvieron en este cabo hasta el lunes siguiente.

Lunes, a 11 del dicho mes partieron del Cabo de San Martín y navegaron obra de cuatro leguas por costa de Nornordeste Su Sudoeste y de alli vuelve la costa al Noroeste; es tierra alta y pelada y el otro día siguiente navegaron en costa de Noroeste Sueste obra de seis leguas; toda esta costa es brava y limpia y el otro día siguiente también navegaron con ruines tiempos obra de cuatro leguas en costa Noroeste Sueste, en tierra hay sierras altas y fragosas, y el jueves siguiente surgieron de tres leguas adelante en una punta que sale a la mar que hace cabo de una banda e de otra, llámase Cabo de Cruz, está en 33 grados, no hay agua, ni leña, ni hallaron señal de Indios.

Partidos del Cabo de la Cruz, hallaron el sábado siguiente dos leguas del Cabo de Cruz por los ruines tiempos en costa de Nornoroeste Susueste y en tierra vieron 
Indios en unas canoas muy pequeñas; la tierra es muy alta e pelada e seca, toda la tierra desde la California aquí es tierra de arenales a la mar, y de aquí empieza la tierra de otra arte, que es tierra de bermejales y de mejor parecer.

Domingo a 17 días del dicho mes anduvieron navegando para seguir su viaje y obra de seis leguas del Cabo de Cruz hallaron un puerto bueno y cerrado y para llegar allá pasaron por una Isleta que está cerca de la tierra firme, en este puerto tomaron agua en una lagunilla de agua llovediza y hay arboleda como de ceybas, excepto que es madera recia; hallaron maderas gruesas e grandes que traía la mar, llámase este Puerto San Mateo; es buen tierra al parecer; hay grandes sabanas e la yerba ( $p$. 178) como la de España y es tierra alta y doblada, vieron unas manadas de animales como ganados que andaban de ciento en ciento o más, que parecían en el parecer y andar como ovejas del Pirú y la lana lengua, tienen cuernos pequeños de un xeme en luengo y tan gordos como el dedo pulgar y la cola ancha y redonda e de longor de un palmo, está en 33 grados y tercio; tomaron posesión en él, estuvieron en este puerto hasta el sábado siguiente.

Sábado a 23 de dicho mes partieron del dicho Puerto de San Mateo y navegaron a luego de la costa hasta el lunes siguiente, que andarían obra de diez e ocho leguas; vieron muy hermosos valles e arboledas e tierra llana y doblada, y no se vieron Indios.

En el martes siguiente y el miércoles navegaron a luego de la costa obra de ocho leguas y pasaron por unas tres Islas despobladas de tierra de ellos; la una de ellos es mayor que las otros que tendrá dos leguas de cumplido, e hace abrigo de los Ponientes; están tres leguas de tierra firme, están en treinta y cuatro grados; este día se vieron en tierra grandes ahumadas, es tierra buena al parecer, e de grandes valles e dentro en la tierra hay sierras altas; llamaron las Islas Desiertas.

El jueves siguiente anduvieron obra de seis leguas por costa de Nornoroeste e descubrieron un Puerto cerrado e muy bueno al cual pusieron nombre San Miguel; esta en treinta e cuatro grados y tercio, y después de surtos en el fueron en tierra que había gente, de los cuales esperaron tres e todos los otros se huyeron, a estos dieron algunos rescates y dijeron por señas que por dentro en la tierra habían pasado gente como los españoles, amostraban tener mucho miedo. Este dicho día a la noche fueron los navios en tierra a pescar con un chinchorro, e parece que estaban ahí unos Indios y comenzáronlos a flechar e hirieron tres hombres.

Otro día por la mañana entraron más adentro del puerto, que es grande, con el batel y trujeron dos muchachos, los cuales no entendían nada por señas, y diéronles sendas camisas e invitáronlos luego.

Y el otro día siguiente por la mañana vinieron a las naos otros tres Indios grandes y por señas dijeron que andaban por la tierra adentro hombres como nosotros, 
barbados y vestidos e armados como los de los navios y señalaban como llevaban ballestas y espadas y hacian ademanes con el brazo derecho como que alanceaban $y$ andaban corriendo como que iban a caballo, y que mataban muchos Indios de los naturales, y que por esto tenían miedo; esta gente es bien dispuestas y crecida, andan cubiertos con pieles de animales, estando en este puerto pasó un temporal muy grande, en pero por ser bueno el puerto no sintieron nada; fue de Oeste Sudoeste (p.179) e Susudoeste tiempo desecho, este es el primer temporal que han pasado; estuvieron en este puerto hasta el martes siguiente. Aquí llamaban a los cristianos Guacamal.

Martes siguiente, a tres días del mes de octubre partieron desde Puerto San Miguel y el miércoles y jueves y viernes caminaron por su derrota obra de 18 leguas a luengo de la costa, por donde veían muchos valles e llanuras y muchas ahumadas, y dentro en la tierra sierras; fueron anochecer junto a unas Islas que están de tierra firme obra de siete leguas, y porque calmó el viento no pudieron llegar esta noche a ellas.

Sábado, a siete días del mes de octubre amanecieron en las Islas, que pusieron nombre San Salvador e la Vitoria, e rugieron en la una de ellas y fueron con el batel en tierra a ver si había gente y como el batel llegaba cerca salió mucha cantidad de Indios de entre las matas e yerbas dando grita e haciendo la perneta e señalando que saliesen en tierra; y veían cómo iban huyendo las mujeres, y de los bateles les hicieron señas que no tuviesen miedo y luego aseguraron y pusieron en tierra sus arcos e flechas, y echaron una canoa buena al agua que cabrían ocho o diez Indios, y vinieron a las naos; diéronles cuentas y rescates con que se holgaron y luego se volvieron; después fueron los españoles en tierra, y estuvieron muy seguros ellos y las Indias e todos. Aquí les señaló un Indio viejo que en la tierra firme andaban hombres como los españoles vestidos y barbudos. No estuvieron en esta Isla más de hasta medio día.

El domingo siguiente, a ocho del dicho mes, allegaron en tierra firme en una bahía grande que llamaron Bahía de los Fumes, por los muchos fumos que en ella vieron; aquí tomaron plática con unos Indios que tomaron en una canoa, los cuales señalaron hacía el Norte que había españoles como ellos; está esta bahía en treinta y cinco grados, y es buen puerto, y buena tierra de muchos valles y llanuras y arboledas.

El lunes siguiente, a nueve días del dicho mes de octubre, partieron de la Bahía de los Fumos y anduvieron este día obra de seis leguas y surgieron en una ensenada grandes y ahi pasaron el otro día siguiente, martes, y anduvieron obra de ocho leguas por costa de Noroeste Sueste y vimos en tierra un pueblo de Indios junto a la mar, y en las casas grandes a manera de las de la Nueva España, y surgieron 
en frente de un valle muy grande en la costa. Aquí vinieron a los navios muchas canoas muy buenas, que cabían en cada una doce o trece Indios y les dieron noticia de cristianos que andaban por la tierra adentro; es costa de Noroeste Sueste, aquí se les dio algunos rescates con que se holgaron mucho. Señalaron que en siete días podían ir adonde andaban los españoles, y estuvo ( $p 180)$ ( $p .181)$ determinado Juan Rodríguez de enviar dos españoles dentro a la tierra. También señalaron que había un río grande. Con estos Indios enviaron una carta a la ventura a los cristianos. Pusieron nombre a este pueblo, Pueblo de las Canoas; andan cubiertos con unos pellejos de animales; son pescadores y comen pescado crudo; también comían maguey. Está este pueblo en treinta y cinco grados e tercio; la tierra adentro es un valle muy fermoso y señalaron que había dentro en aquel valle mucho maíz e mucha comida, parece dentro de aqueste valle unas sierras muy altas, tierra muy doblada; llaman a los cristianos Taquimine; aquí tomaron posesión, aquí estuvieron hasta el viernes a trece días del dicho mes.

Viernes, a trece días del dicho mes de octubre, partieron del Pueblo de las Canoas para su viaje y anduvieron este día seis o siete leguas, y pasaron de tierra de dos islas grandes que tendrán cuatro leguas cada una y estarán cuatro leguas de tierra firme. Son despobladas porque no hay agua en ellas y tiene buenos puertos; va la costa de la tierra firme al Oes Noroeste; es tierra llana y de muchas sabanas y arboledas, y el sábado siguiente corrieron su vía, y anduvieron dos leguas no más y surgieron enfrente de un valle muy fermoso e muy poblado, e tierra llana e de muchas arboledas. Aquí vinieron canoas con pescado a rescatar; quedaron grandes amigos. $Y$ el domingo siguiente, a quince días del dicho mes, anduvieron navegando su viaje a luengo de la costa obra de 10 leguas y siempre hubo muchas canoas, porque toda la costa es pobladísima, y venían muchos Indios siempre en las naos, y nos señalaban los pueblos, y los nombraban por sus nombres, que son, Xuco, Bis, Soposo, Alloc, Xabasgua, Xocotoc, Potoltec, Nacbuc, Quelqueme, Mixingua, Misesopano, Elquis, Coloc, Mugu, Xagua, Anacbuc, Partocac, Susuquey, Quanmu, Gua, Asimu, Aguir, Casalic, Tucumu, Incpupu. Todos estos pueblos están desde el primer Pueblo de las Canoas que se Xucu hasta aquí; están en muy buena tierra, muy buenas llanuras e muchas arboledas e sabanas; andan vestidos con pellejos, decían que dentro en la tierra había muchos pueblos e mucho maíz de allí a tres jornadas; llaman al maíz Oep; y también que había muchas vacas; llaman a la vacas Cae, también nos dieron noticia de gente barbada e vestida. Pasaron este día de tierra de una Isla grande que tendrá quince leguas de largo y dijeron que estaba muy poblada y que había los pueblos siguientes: Niquipos, Maxul, Xugua, Nitel, Macamo, Nimitapal. Llamaron 
a la Isla San Lucas, habrá de aquí al pueblo de las Canoas, 18 leguas, estará la Isla, de tierra firme, seis leguas.

Lunes 16 días del dicho mes, navegando a luengo de la costa, anduvieron cuatro leguas y surgieron a la tarde enfrente de dos pueblos; y (acaba la p. 181) también este día siempre vinieron canoas con las naos, y señalaron que adelante habías canoas muy mayores.

El martes siguiente, diez y siete de dicho mes, anduvieron tres leguas con tiempos bonancibles y fueron con las naos desde que amaneció muchas canoas, y el Capitán siempre les daba muchos rescates; e toda esta costa por donde han pasado está muy poblada; traíanles mucha sardina fresca y muy buena, dicen que a la tierra adentro hay muchos pueblos e mucha comida; éstos no comían cosa de maíz, andaban vestidos de pellejos y traen los cabellos muy pargos y revueltos con unos cordeles muy largos y metidos por entre los cabellos y aquellos cordeles muchas dagas de pedernales y de hueso y de madera; la tierra es muy excelente al parecer.

Miércoles a 18 días del dicho mes anduvieron corriendo la costa hasta las diez horas y veían toda la costa poblada, e por que llevaban el viento fresco no llegaron canoas; allegaron a una punto que hace cabo como Galera y le pusieron Cabo de Galera y está en 36 grados largos; e porque les dio Noroeste fresco fueron el bordo de la mar y descubrieron dos Islas, la una grande, que tendrá ocho leguas de costa de Leste oeste, y la otra tendrá cuatro leguas, y en esta pequeña hay un puerto bueno y son pobladas; están diez leguas de tierra firme, llámanse las Islas de San Lucas. De la tierra firme hasta el Cabo de Galera se corre al Oeste cuarta del Nordeste y desde el Pueblo de las Canoas hasta el Cabo de Galera es una Provincia muy poblada e llamada Xuxu; tiene muchas lenguas diversas unas de otras; tienen muy grandes guerras unos con otros; hay desde el Pueblo de las Canoas hasta el Cabo de Galera treinta leguas; estuvieron en estas Islas hasta el miércoles siguiente porque hizo mucho temporal.

Miércoles a veinte e cinco días del dicho mes partieron de las dichas Islas de la que más estaba a barlovento; tiene un puerto muy bueno, que por todos los tiempos de la mar no se les dará nada estando dentro; llamaron la Posesión, este día anduvieron poco porque no había tiempo y a la media noche siguiente les dio un viento Susudoeste y Oes Sudoeste con lluvia que se vieron en aprieto, porque les era travesía y estaban cerca de tierra, y no pudieron doblar el Cabo de un bordo ni de otro, y el jueves siguiente e vísperas les alargó el viento al Sur en que andarían en su derrota diez leguas en costa de Nornoroeste Susueste, toda esta costa es poblada, al parecer buena tierra; esta noche se tuvieron a la mar porque les era el tiempo en travesía, y el viernes y el sábado y el domingo siguiente anduvieron con vientos 
contrarios barloventeando a una parte y a otra sin poder ganar nada, y estaban en 36 grados y medios, diez leguas del Cabo de Galera; así mismo anduvieron lunes y martes a 31 (termina p.182) día dicho mes, víspera de Todos Santos, volteando a una parte y a otra, y quisieron allegar a la tierra firme en busca de un río grande que llevaban noticia de él, que estaba de la otra parte del Cabo de la Galera, e porque hacía en tierra muestras de ríos y no hallaron ningún río, tampoco surgieron aquí, porque era costa muy brava, hallaron en este mes en esta costa los tiempos como en España desde los 34 grados arriba y con mucho frío a las mañanas $y$ a las tardes, $y$ con los temporales, grandes cerrazones y los aires pesados.

Miércoles a la media noche primero día de noviembre a la media noche tengo del bordo de la mar, les dio mucho tiempo del Nornoroeste que no les dejaba llevar palmo de vela y al alba refrescó en tanta manera que no pudieron hacer menos de ir a buscar abrigo y fueron al abrigo de Cabo de Galera, y alli surgieron y fueron en tierra y porque había un pueblo grande que llaman Xexo e no parecía estar muy a mano la leña, acordaron de ir al Pueblo de las Sardinas porque estaba el agua y la leña muy cerquita e a mano; llamaron a este abrigo de Galera, Puerto de Todos Santos. El jueves siguiente se fueron al Pueblo de las Sardinas donde estuvieron tomando agua y leña tres días, e los naturales de la tierra les ayudaban e traían la leña y el agua a las naos; llámase este Pueblo del Puerto de Sardinas Cicacut y los otros que están desde allí hasta el Cabo de Galera son: Ciucut, Anacot, Maquinanos, Paltatre, Anacoat, Olesino, Cascat, Paltocac, Tocane, Opia, Opistopia, Nocos, Yutum. Quinam. Micoma, Garomisopona; es Señora de estos pueblos una India vieja que vino a la naos y durmió dos noches en la Capitana, y lo mismo muchos Indios. El pueblo de Ciucut parecía ser cabecera de otros pueblos porque venían alli de otros pueblos al llamado de aquesta Señora; llámase el pueblo que está al cabo Xexo. Desde este Puerto al Pueblo de las Canoas es otra provincia que llaman Xuxu, tienen sus casas redondas y cubiertas muy bien hasta el suelo; andan cubiertos de pieles de muchas manera de animales, comen bellotas de encinas y unas semillas que es tan gruesa como maíz y es blanca de que hacen tamales, tiene buena comida. Dicen que a la tierra adentro hay mucho maíz y que andan allí hombres como nosotros, e está este puerto en $\mathbf{3 5}$ grados y dos tercios.

Lunes a 6 del dicho mes de noviembre partieron del dicho puerto de Sardinas e aquel día no anduvieron casi nada e hasta el viernes siguiente anduvieron con muy poco tiempo; este día llegamos al Cabo de la Galera, por todo este camino no podían valerse de Indios que les venían a bordo con agua y pescado y amostraban mucho amor; tienen en sus pueblos sus plazas grandes y tienen un ruedo como cerca, y alrededor del ruedo (termina $p$. 183) tienen muchas losas de piedra 
hincadas en tierra que salen encima tres palmos y en medio de las cercas tienen muchos maderos hincados como masteles y muy espesos; tienen mucha pintura en los mismos palos y creemos que adoran en ellos, porque cuando bailan andan bailando alrededor de la cerca.

\section{El sábado siguiente día de San Martín a 11 días del dicho mes de} noviembre anduvieron navegando a luego de la tierra, y hállaronse esta mañana doce leguas del cabo en el mismo paraje donde arribaron primero y todo este día tuvieron buen viento que caminaron a luego de la costa de Noroeste Sueste, anduvieron bien 20 leguas; toda esta costa que anduvieron este día es costa brava sin abrigo ninguno y va una cordillera de sierra en toda ella muy alta, y tan alta es a la mar, como a la tierra dentro bate la mar en ella; no vieron poblazón, ni fumos, $y$ toda la costa que no tiene abrigo de Norte está despoblada; pusieron nombre a las sierras, las Sierras de San Martín; están en 37 grados y medio; el remate de ellas y de estas sierras al Noroeste hace un cabo que sale a la mar que está en $\mathbf{3 8}$ grados, pusiéronle Cabo de San Martín.

Esta dicha noche de sábado a 4 horas de la noche estando en la mar obra de seis leguas de la costa al reparo esperando al día con viento Sueste, cargó tanto tiempo de Susueste e el Susudoste von lluvia y cerrazón que no podían tener palmo de vela e hízoles correr con un papo de vela del trinquete con mucho trabajo toda la noche y el domingo siguiente cargó mucho más el tiempo deshecho que duró el día y la noche hasta el lunes siguiente a medio día y era tan grande la fortuna como puede haber en España; el sábado a la noche perdieron de vista la Compañía.

El lunes a 13 días del dicho mes de noviembre a hora de vísperas abonazó el viento y saltó al Oeste e luego dieron las velas y fueron en busca de la Compañía a la vuelta de la tierra, rogando a Dios que les deparase, que recelaron mucho que sería perdida; corrieron al Norte e al Nornoroeste con viento Oeste y Oes Noroeste; $y$ el martes siguiente en amaneciendo hubieron vista de la tierra y tuvieron que andar hasta la tarde y fueron a reconocer en una tierra muy alta, y anduvieron a luego de la costa por ver si había algún puerto donde reparase y era tanta la mar de leva que había que era espanto ver, y la costa brava y sierras muy altas, y a la tarde se pararon al reparo, es costa de Noroeste Sueste; reconocieron la tierra en una punta que sale a la mar que hace cabo, y está cubierta de arboledas la punta, y está en 40 grados.

Miércoles a 15 de dicho mes tuvieron vista de la Compañera de que dieron muchas gracias a Dios que la tuvieron por perdida, e arribaron sobre (termina $p$. 184) ella, juntáronse a la tarde. Los del otro navio pasaron más trabajo y riesgo que los de la Capitana por ser el navío pequeño y no tener puente; esta tierra 
donde andaban es al parecer muy buena, empero no vieron Indios, ni fumos; hay grandes sierra e cubiertas de nieve, hay mucha arboleda. A la noche amainaron y se pusieron a reparo.

Jueves siguiente a 16 del dicho mes de noviembre amanecieron sobre una ensenada grande que venía de vuelta que parecía haber puerto e río, y anduvieron barloventeando este dicho día y la noche, y el viernes siguiente hasta que vieron que ni había río, ni abrigo ninguno; y para tomar posesión echaron ancla en 45 brazas; no osaron ir a tierra por la mucha mar que había, estaba esta ensenada en 39 grados largos y toda ella está llega de pinos hasta la mar, pusiéronle nombre la Bahía de los Pinos. La noche siguiente estuvieron al reparo hasta el día siguiente.

El sábado siguiente corrieron la costa y halláronse a la noche sobre el Cabo de San Martín; toda esta costa de este día es muy brava, y hay mucha mar de leva y la tierra es muy alta, hay montañas que se van al cielo, y la mar bate en ellas, yendo navegando cerca de tierra parece que quieren caer sobre las naos; están llenas de nieve a la cumbre, pusiéronle nombre las Sierras Nevadas, y al principios de ellas hace un cabo que sale a la mar, que le pusieron nombre Cabo de Nieve; córrese la costa Nornoroeste Susueste, no parece que habitan Indios en esta costa. Está este Cabo de Nieve en 38 grados y dos tercios, y siempre que ventaba Noroeste hacia claro y limpio el tiempo.

Jueves 25 días del mes allegaron de vuelta en las Islas de San Lucas a una de ellas llamada Posesión y corrieron toda la costa punta por punta desde el Cabo de Pinos a ellas, y no hallaron abrigo ninguno porque de necesidad hubieron de volver a la dicha Isla, porque estos días pasados ventó Oest Noroeste muy mucho y venía la mar de leva muy grandes; desde Cabo de Martín hasta Cabo de Pinos no vimos Indios ningunos, y cáusalo la costa ser brava y desabrigada y fragosa en la costa $y$ de la banda del Sureste del Cabo de Martín en 15 leguas hallaron la tierra poblada e muchas ahumadas porque es buena tierra; empero desde el Cabo de Martín hasta los 40 grados no vimos señal de Indios; está el Cabo San Martín en 37 grados y medio.

Estando invernando en esta Isla de Posesión a 3 días del mes de enero de 1543 falleció de esta presente vida Juan Rodríguez Cabrillo, Capitán de los dichos navios de una caída que dio en la dicha Isla al tiempo que la otra vez estuvieron en ella, de que se quebró un brazo junto al hombro. Dejó por Capitán al Piloto mayor que era un Bartolomé Ferrelo, natural (termina p. 185) levantisco y les encargó mucho al tiempo de su muerte que no dejasen de descubrir cuanto posible fuese por toda aquella costa. Pusieron nombre a la Isla, la Isla de Juan Rodríguez; llaman los Indios a esta Isla Ciquimuymu y a otra llaman Nicalque, e a la otra llaman Limu; en esta Isla de la Posesión hay dos pueblos, al uno llaman Nicochi y el otro Coycoy 
y el otro Estocolco; en la otra Isla hay ocho pueblos que son: Niquesesquelua, Poele, Pisqueno, Pualnacatup, Patiqui, Patiquilid, Ninumu, Muoc, Piliduay, Lilibeque.

Los Indios de estas Islas son muy pobres, son pescadores, no comen otra cosa si pescado no, duermen en el suelo, todo su negocio y ejercicio es pescar; en cada casa dicen que hay cincuenta ánimas; viven muy aporcadamente, andan desnudos. Estuvieron en estas Islas desde 25 de noviembre hasta 19 de enero. En todo este tiempo, que fueron casi dos meses, hizo muy recios tiempo de invierno y de agua; los tiempos que más siguieron fueron Oest Sudoeste y Susudoeste y Oest Noroeste, hubo tiempo muy desechos.

Viernes 19 días del mes de enero de 1543 se hicieron a la vela de la Isla Juan Rodríguez, que se dice Ciquimuymu, para ir a la tierra firme en busca de algunos bastimentos para su jornada, y en saliendo del puerto les dio mucho tiempo de Oest Noroeste, que les hizo arribar a las otras Islas de San Lucas y surgieron en la Isla de Limun que pusieron nombre San Salvador y tuvieron necesidad de levantarse otra vez de alli porque no había puerto más del abrigo de las Islas, y tornó el viento a la travesía y anduvieron a la redonda de estas Islas ocho días con los tiempos muy ruines, abrigándose con las mismas Islas de los tiempos ruines; y a 27 días del dicho entraron en el mismo puerto de la Isla de Juan Rodríguez, donde estuvieron primero; el mayor trabajo que tenían era por los tiempos no ser fijos, que andaban mudándose de uno a otro; los que más afijan son del Oes Noroeste al Oest Sudoeste.

Martes a 29 días del dicho mes de enero partieron de la Isla Juan Rodríguez para la Isla de San Lucas, que está en medio de las otras, para tomar ciertas anclas que habian dejado con un tiempo, no las pudiendo tomar, las cuales tomaron e tomaron agua.

Partieron de esta Isla de San Lucas, lunes a 12 días del mes de febrero que no pudieron más presto por los ruines tiempos que les hizo de vientos e muchas nieves; es poblada y la gente es como la de la otra Isla; Ilámanle los Indios Nicalque; hay tres pueblos en ella que se llaman Nicochi, Coycor, Coloco; este día fueron al Puerto de las Sardinas a tomar (termina p. 186) leña e otras cosas necesarias para su viaje, que no las había en las Islas.

Miércoles 14 días del dicho mes partieron del Puerto de Sardinas, habiendo tomado una batelada de leña y no osaron estar más allí por la mucha mar que había; no hallaron tantos Indios como primero, ni pesquería ninguna por causa del invierno. Los naturales comían de las bellotas de las encinas e otra semilla, e yerbas del campo crudas. De aquí fueron a la Isla de San Salvador porque estaban allá más seguros de los temporales para poderse hacer a la vela para poder correr por la mar. 
Domingo a 18 días del mes de febrero partieron de la Isla de San Salvador con el viento Nordeste bonancible e corrieron al Sudoueste porque dijeron que había hacia el Sudoeste otras Islas; fueron a anochecer este día obra de doce leguas de las Islas de San Salvador y vieron seis Islas de ellas grandes y de ellas pequeñas- Este día se les murió un marinero y el lunes siguiente amanecieron a barlovento de las Islas a la mar obra de diez leguas y con el viento Oest Noroeste fueron del bordo de la mar cinco días al Sudoeste y al cabo que anduvieron obra de cien leguas hallaron los tiempos más recios y mucha mar; y jueves a 22 días del dicho mes de febrero hicieron otra vuelta por la tierra para ir en busca de Cabo de Pinos con viento Suroeste que les duró tres días y cada día iba arreciando, y el domingo siguiente en amaneciendo tuvieron vista del Cabo de Pinos y fueron este día a anochecer veinte leguas a barlovento en costa de Noroeste Sueste y es brava sin abrigo; no se vio fumo ninguno en tierra, e vieron una punta que hacía como remate de tierra que volvía la costa Nornoroeste; a la media noche saltó el viento al Sursudoeste y corrieron al Oes Noroeste hasta el día, y por la mañana saltó el viento al Oes Sudoeste muy recio que duró hasta el martes siguiente; corrieron al Noroeste.

Martes a 27 días del dicho mes volvió el tiempo al Sursudoeste que duró todo el día; corrieron al Oest Noroeste con los trinquetes bajos, porque ventaba recio; en anocheciendo saltó el viento al Oeste; corrieron toda la noche al Sur con pocas velas; había mucha mar que los comía.

El miércoles siguiente, a 28 días del dicho mes, en amaneciendo saltó el viento al Sudoeste franco, e no ventó mucho; este día tomaron el altura en 43 grados; hacia la noche regresó el viento y saltó al Sursudoeste; corrieron esta noche al Oest Noroeste con mucho trabajo, y el jueves en amaneciendo saltó el viento al Sudoeste con mucha furia, y los mares venían de muchas partes, que les fatigaba mucho e pasaban por encima de los navios, que no tener puentes si Dios no los socorriera no pudieran escapar, y no pudiendo tenerse al reparo, de necesidad corrieron en popa (termina p. 187) al Noreste a la vuelta de la tierra e tuviéndose ya por perdidos se encomendaron a Nuestra Señora de Guadalupe e hicieron mandas e corrieron ansí hasta las tres horas después de mediodía con mucho miedo y trabajo, porque veían que iban a perderse y veían ya muchas señales de tierra que estaban cerca, así de pájaros como de palos muy frescos que salían de algunos ríos, aunque con la gran cerrazón no parecía la tierra y a esta hora los socorrió la Madre de Dios con la gracia de su hijo e vino un aguacero de la parte del Norte muy recio que les hizo correr toda la noche y el otro día siguiente hasta el Sol puesto con los trinquetes bajitos; e porque había mucha mar del Sur embestíales cada vez por la proa y pasaba por ellos como por una peña, y saltó el viento al Noroeste e al Nornoroeste con mucha furias que 
les hizo correr hasta el sábado a tres de marzo al Sureste y al Es Sueste, con tanta mar que los traía desatinados, que si Dios y su bendita Madre milagrosamente no los salvara, no pudieran escapar. El sábado a medio día abonanzó el tiempo y quedó al Noroeste de que dieron muchas gracias a Nuestro Señor, en la comida también pasaban fatiga, por no tener sino solo bizcocho e dañado.

Parecéles que queda un río muy grande, de que tuvieron mucha noticia entre 41 grados e 43, porque vieron muchas señales de ello, este día a la tarde reconocieron al Cabo de Pinos, y por la mucha mar que había no pudieron hacer menos de correr la costa de vuelta en busca de puerto; pasaban mucho frío.

Lunes a cinco días del dicho mes de marzo de 1543 en amaneciendo se hallaron en la Isla de Juan Rodríguez y no osaron entrar en el puerto por causa de la mucha tormenta que andaba que rompía la mar en la entrada del puerto en 15 brazas; era el tiempo Nornoroeste; es angosta la entrada; corrieron al abrigo de la Isla de San Salvador de la banda del Sueste, y la noche pasada viniendo con mucho temporal con solamente con sendos papos de velas en los trinquetes, se les desapareció el otro navio que sospecharon que la mar lo había comido, y no lo pudieron descubrir más, ni aún después que amaneció; creen que estarían en 44 grados cuando les tomó la tormenta postrera que les hizo arribar.

Jueves a ocho días del dicho mes partieron de la Isla de San Salvador para ir en tierra firme en busca del otro navio y fueron al Pueblo de las Canoas e fueron a la Isla de San Salvador, e tampoco hallaron la Compañía.

Domingo 11 del dicho mes allegaron al Puerto de San Miguel y tampoco hallaron la Compañía, ni nuevas de ella; aquí esperaron seis días (termina p. 188) aquí tomaron dos muchachos para lenguas para llevar a la Nueva España y dejaron ciertas señas para si llegase el otro navío

Sábado 17 días del dicho mes partieron del dicho Puerto de San Miguel, el domingo siguiente llegaron en la Bahía de San Mateo y tampoco hallaron rastro del otro navío.

Domingo a 18 días del dicho mes en la parte partieron de esta bahía de San Mateo y el miércoles siguiente, a 21 del dicho mes, llegaron al Puerto de la Posesión, y tampoco hallaron nuevas de la Conserva; esperaron dos días sin entrar en el puerto, porque no osaron entrar en él por el mucho Noroeste que ventaba, y porque se les cortó el amarra, de necesidad se levantaron.

Viernes a 23 días del dicho mes partieron del Puerto de la Posesión y el sábado siguiente a media noche llegaron a la Isla de Cedros y estando en ella el lunes siguiente a 26 días del dicho mes allegó el otro navio en Isla de Cedros, de que se holgaron mucho, e dieron muchas gracias a Dios; este navio pasó en la Isla de Juan 
Rodríguez de noche por encima de unos bajos que pensaron perderse y prometieron los marineros de irse a su Iglesia desnudos en carnes, e nuestra Señora los libró.

Lunes a dos días del mes de abril partieron de la Isla de Cedros la vuelta de la Nueva España, porque no tenían bastimentos para tornar acometer a descubrir la costa. Llegaron en el Puerto de Navidad, sábado a 14 días del dicho mes de abril.

Vino por Capitán de los navios Bartolomé Ferrel, Piloto mayor de los dichos navios, en falta de Juan Rodríguez Cabrillo, que murió en la Isla de la Posesión. Venían hombres en los dichos navios. 